\title{
Meridional Structure of the Seasonally Varying Mixed Layer Temperature Balance in the Eastern Tropical Pacific
}

\author{
Michael J. McPhaden and Meghan F. Cronin \\ NOAA/Pacific Marine Environmental Laboratory, Seattle, Washington \\ DAi C. McCluRG \\ NOAA/Pacific Marine Environmental Laboratory, and Joint Institute for the Study of the Atmosphere and Ocean, University of \\ Washington, Seattle, Washington
}

(Manuscript received 26 June 2007, in final form 23 November 2007)

\begin{abstract}
The eastern tropical Pacific Ocean is important climatically because of its influence on the El NiñoSouthern Oscillation (ENSO) cycle and the American monsoon. Accurate prediction of these phenomena requires a better understanding of the background climatological conditions on which seasonal-tointerannual time-scale anomalies develop in the region. This study addresses the processes responsible for the seasonal cycle of sea surface temperature (SST) in the eastern tropical Pacific using 3 yr (April 2000-March 2003) of moored buoy and satellite data between $8^{\circ} \mathrm{S}$ and $12^{\circ} \mathrm{N}$ along $95^{\circ} \mathrm{W}$. Results indicate that at all latitudes, surface heat fluxes are important in the mixed layer temperature balance. At $8^{\circ} \mathrm{S}$, in a region of relatively deep mean thermocline and mixed layer, local storage of heat crossing the air-sea interface accounts for much of the seasonal cycle in SST. In the equatorial cold tongue and the intertropical convergence zone, where mean upwelling leads to relatively thin mixed layers, vertical turbulent mixing with the upper thermocline is a major contributor to SST change. Lateral temperature advection by seasonally varying large-scale currents is most significant near the equator but is generally of secondary importance. There is a hemispheric asymmetry in seasonal SST variations, with larger amplitudes in the Southern Hemisphere than in the Northern Hemisphere. This asymmetry is mainly due to forcing from the southerly component of the trade winds, which shifts the axis of equatorial upwelling south of the equator while creating an oceanic convergence zone to the north that limits the northward spread of cold upwelled water. In general, results support the Mitchell and Wallace hypothesis about the importance of southerly winds and ocean-atmosphere feedbacks in establishing seasonally varying climatological conditions in the eastern tropical Pacific.
\end{abstract}

\section{Introduction}

The eastern tropical Pacific is a key region for understanding climate variability on seasonal-to-interannual time scales. Variability in this region affects the climate of western North and South America and, through atmospheric teleconnections associated with the El Niño-Southern Oscillation (ENSO) cycle, the climate of the globe. Also, strong ocean-atmosphereland interactions produce a significant hemispheric asymmetry in the climatology of the region that affects

Corresponding author address: Michael J. McPhaden, NOAA/ Pacific Marine Environmental Laboratory, Seattle, WA 981156349.

E-mail: michael.j.mcphaden@noaa.gov the seasonal evolution of convection and rainfall (Mitchell and Wallace 1992; Xie 1996; Philander et al. 1996). Three clearly identifiable regimes are evident in a relatively narrow band of latitudes spanning the equator. These are the arid stratus deck region over the cool waters of the southeastern Pacific; the equatorial cold tongue where ocean circulation strongly constrains sea surface temperature (SST) through upwelling dynamics; and the intertropical convergence zone (ITCZ), which is a region of deep convection and heavy rainfall found over the warm water pool to the north of the equator.

Research over the past 40 years has established a basic qualitative understanding of the physical processes important for generating observed variability in the region (Kessler 2006). However, quantitatively we are limited by a lack of adequate data to define relevant 
phenomena and to diagnose observed fluctuations in the mixed layer heat balance, which governs SST. These limitations manifest themselves in an inability to formulate coupled ocean-atmosphere models of the climate system capable of realistically simulating observed variability. In particular, most coupled models exhibit some combination of systematic errors that involve cold biases in equatorial cold tongue SSTs, warm biases in the stratus deck region, and/or unrealistic double ITCZs straddling the equator (Mechoso et al. 1995; Davey et al. 2002; Large and Danabasoglu 2006; Xie et al. 2007; Lin 2007).

In this paper we will describe the seasonal cycle and its meridional structure along $95^{\circ} \mathrm{W}$ between $8^{\circ} \mathrm{S}$ and $12^{\circ} \mathrm{N}$ using moored time series from the Tropical Atmosphere Ocean (TAO) array (McPhaden et al. 1998), enhanced for the Eastern Pacific Investigation of Climate (EPIC) (Cronin et al. 2002). Based on this description, we will then diagnose the upper-ocean heat balance to better understand oceanic and atmospheric processes affecting the seasonal cycle of SST. This work builds on and extends previous empirical studies of the mixed layer heat balance on seasonal time scales in the region, most notably those of Swenson and Hansen (1999) and Wang and McPhaden (1999). These studies described the relative importance of surface heat fluxes, upwelling, turbulent vertical mixing, horizontal advection, and horizontal eddy transports in the mixed layer heat balance of the eastern Pacific. However, the Swenson and Hansen analysis was for a large area average between $4^{\circ} \mathrm{N}$ and $4^{\circ} \mathrm{S}, 98^{\circ}$ and $130^{\circ} \mathrm{W}$; Wang and McPhaden considered only balances on the equator at four mooring locations between $110^{\circ} \mathrm{W}$ and $165^{\circ} \mathrm{E}$. More recently, Wijesekera et al. (2005) considered the mixed layer heat balance at $10^{\circ} \mathrm{N}, 95^{\circ} \mathrm{W}$ during the EPIC Processes in the Coupled Ocean-Atmosphere System 2001 (EPIC2001) field experiment. They found that most terms in the heat balance contributed to changes in SST, but their study was for one month only in September 2001.

Our analysis also complements model studies of the seasonal cycle in the tropical Pacific such as the forced ocean simulations of Chen et al. (1994) and Kessler et al. (1998) and the regional coupled ocean-atmosphere study of de Szoeke et al. (2007). Model studies provide detailed information on physical processes in an internally consistent dynamical framework and they also allow for examination of factors governing the mixed layer heat balance at much higher spatial resolution. However, model results are sensitive to the specification of parameterized physics, imposed boundary conditions, and forcing fields. Hence, they can offer only qualitative guidance on processes controlling the mixed layer heat balance in the eastern Pacific. Against this backdrop, analysis of the EPIC time series affords a valuable and unique opportunity to examine the meridional structure of the seasonal heat balance using highquality synoptic datasets in the eastern Pacific where hemispheric asymmetries are pronounced.

The remainder of this paper is organized as follows. Section 2 describes the datasets used in this study. Section 3 describes mean, seasonal, and interannual variations in the region as background for a discussion of the surface mixed layer temperature balance in section 4 . Section 5 provides an interpretation of the mixed layer temperature balance residuals, focusing on three distinct regions: the equatorial cold tongue, the region under the influence of the ITCZ, and the southern extreme of the section at $8^{\circ} \mathrm{S}$. The paper concludes with a summary and discussion of the most important results.

\section{Data}

Our analysis relies primarily on data along $95^{\circ} \mathrm{W}$ from the TAO array, which was enhanced for the EPIC field program from 1999 to 2003. The overall objective of EPIC was to improve our understanding of processes affecting SST and coupled ocean-atmosphere boundary layer interactions in the eastern tropical Pacific. Enhancements to TAO along $95^{\circ} \mathrm{W}$ included additional Autonomous Temperature Line Acquisition System (ATLAS) moorings (Milburn et al. 1996) at $3.5^{\circ}, 10^{\circ}$, and $12^{\circ} \mathrm{N}$ (Fig. 1), plus increased instrumentation on each of the ten $95^{\circ} \mathrm{W}$ moorings for measurement of air-sea fluxes and ocean mixed layer processes. Surface meteorological measurements include winds, relative humidity, air temperature, shortwave radiation, downwelling longwave radiation, rain rate, and atmospheric pressure (Cronin et al. 2006b). All meteorological measurements were made at heights of 3-4 $\mathrm{m}$ above the surface. Ocean temperatures were measured at the surface and 12 subsurface depths $(5,10,20,40,60,80,100$, $120,140,180,300$, and $500 \mathrm{~m})$. SST was measured at a depth of $1 \mathrm{~m}$, so it is a bulk estimate that does not include skin temperature effects or the effects of shallow temperature gradients on calm, sunny days (Fairall et al. 1996). Conductivity (for determining salinity) was measured at the surface $(1 \mathrm{~m})$ and six subsurface depths $(5,10,20,40,80$, and $120 \mathrm{~m})$. Horizontal velocity was measured at $10-\mathrm{m}$ depth in the surface mixed layer by SonTek Argonaut current meters. Currents were also measured at $40-\mathrm{m}$ depth between $5^{\circ} \mathrm{N}$ and $5^{\circ} \mathrm{S}$.

Data were transmitted to shore via Service Argos as daily averages. Data were also internally recorded every $10 \mathrm{~min}$, with the exception of barometric pressure (recorded at 1-h intervals), currents (at 20-min inter- 


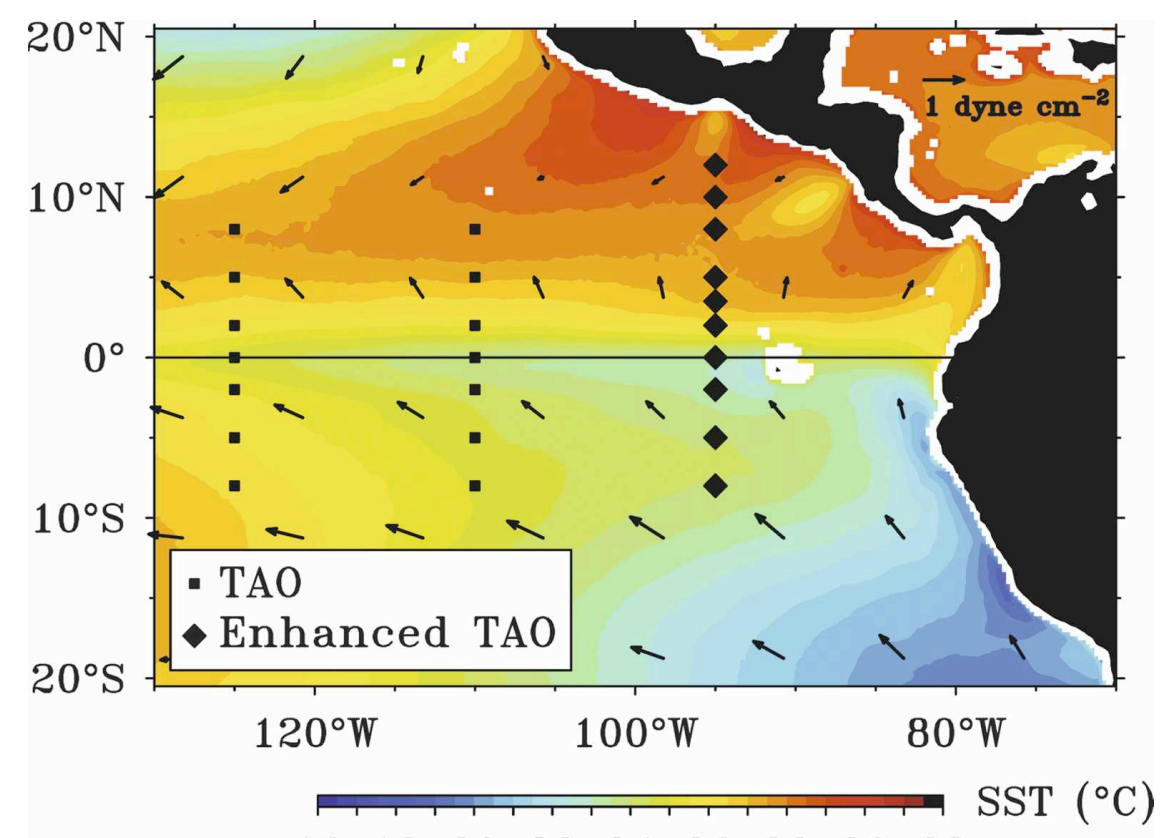

$\begin{array}{lllllllll}16 & 18 & 20 & 22 & 24 & 26 & 28 & 30 & 32\end{array}$

FIG. 1. Schematic of the TAO array with EPIC enhancements along $95^{\circ} \mathrm{W}$ superimposed on mean TMI SSTs and QuikSCAT wind stress for April 2000-March 2003. See text for a discussion of mooring sensors.

vals), and rain rate and radiation (at 1- and 2-min intervals, respectively). Details of sampling schemes, instrumentation, sensor accuracies, and mooring configurations can be found at http://www.pmel.noaa.gov/tao/ epic.

There is a wide range of variability on intraseasonal, seasonal, and interannual time scales along $95^{\circ} \mathrm{W}$, as illustrated by daily time series at $3.5^{\circ} \mathrm{N}$ (Fig. 2) during the 3-yr EPIC enhanced monitoring period (1 April 2000-31 March 2003). The data gaps in these time series provide an indication of data return, which was mainly limited by fishing vandalism in the region and, for some sensors like the current meters, instrumental problems. Another indication of data return is the number of months with more than 15 daily average values over the 3-yr period (Fig. 3). The overall data return based on daily averaged data was $79 \%$ (Table 1), with velocity measurements at the low end $(40 \%)$ and SST at the high end $(90 \%)$.

We also use satellite-based estimates of SST, surface wind velocity and stress, and surface currents for the period 2000-03. SST is obtained from the Tropical Rainfall Measuring Mission (TRMM) Microwave Imager (TMI) on a $0.25^{\circ}$ latitude $\times 0.25^{\circ}$ longitude daily grid (http://www.ssmi.com/tmi/). We prefer this product to the Reynolds et al. (2002) blended satellite/in situ SST analysis for our purposes since clouds like those found in the eastern tropical Pacific ITCZ do not affect
TMI microwave retrievals as they do the infrared satellite retrievals used by Reynolds et al. Surface wind stress, processed to weekly averages on a $0.5^{\circ} \times 0.5^{\circ}$ grid, is derived from the SeaWinds scatterometer onboard the Quick Scatterometer (QuikSCAT) satellite (http://www.ifremer.fr/cersat). Both QuikSCAT winds and TMI SSTs were regridded to $1^{\circ} \times 1^{\circ}$ resolution for further analysis. For 3-day averages, root-mean-square (rms) differences between TAO and QuikSCAT wind speeds are $\sim 0.7 \mathrm{~m} \mathrm{~s}^{-1}$, and $\mathrm{rms}$ differences between TAO and TMI SSTs are $\sim 0.4^{\circ} \mathrm{C}$ (Chelton et al. 2001). Averaging in space and time reduces these errors further, so the satellite data can be used interchangeably with the mooring data in our heat balance analysis.

We also make use of the Ocean Surface Current Analyses Real Time (OSCAR), which is representative of flow in the mixed layer at $15-\mathrm{m}$ depth and is available on a $1^{\circ} \times 1^{\circ}$ grid (Bonjean and Lagerloef 2002). This velocity product is derived from satellite altimetry measurements of ocean surface height, surface winds, and a model of ocean currents based on frictional and geostrophic dynamics in a stratified ocean. OSCAR currents are available at 5-day intervals, although they have an effective resolution of 10 days because of the 10-day sampling of the satellite altimeter data. In this study, we use a version of the OSCAR currents smoothed over $2^{\circ}$ of latitude and $10^{\circ}$ of longitude. 


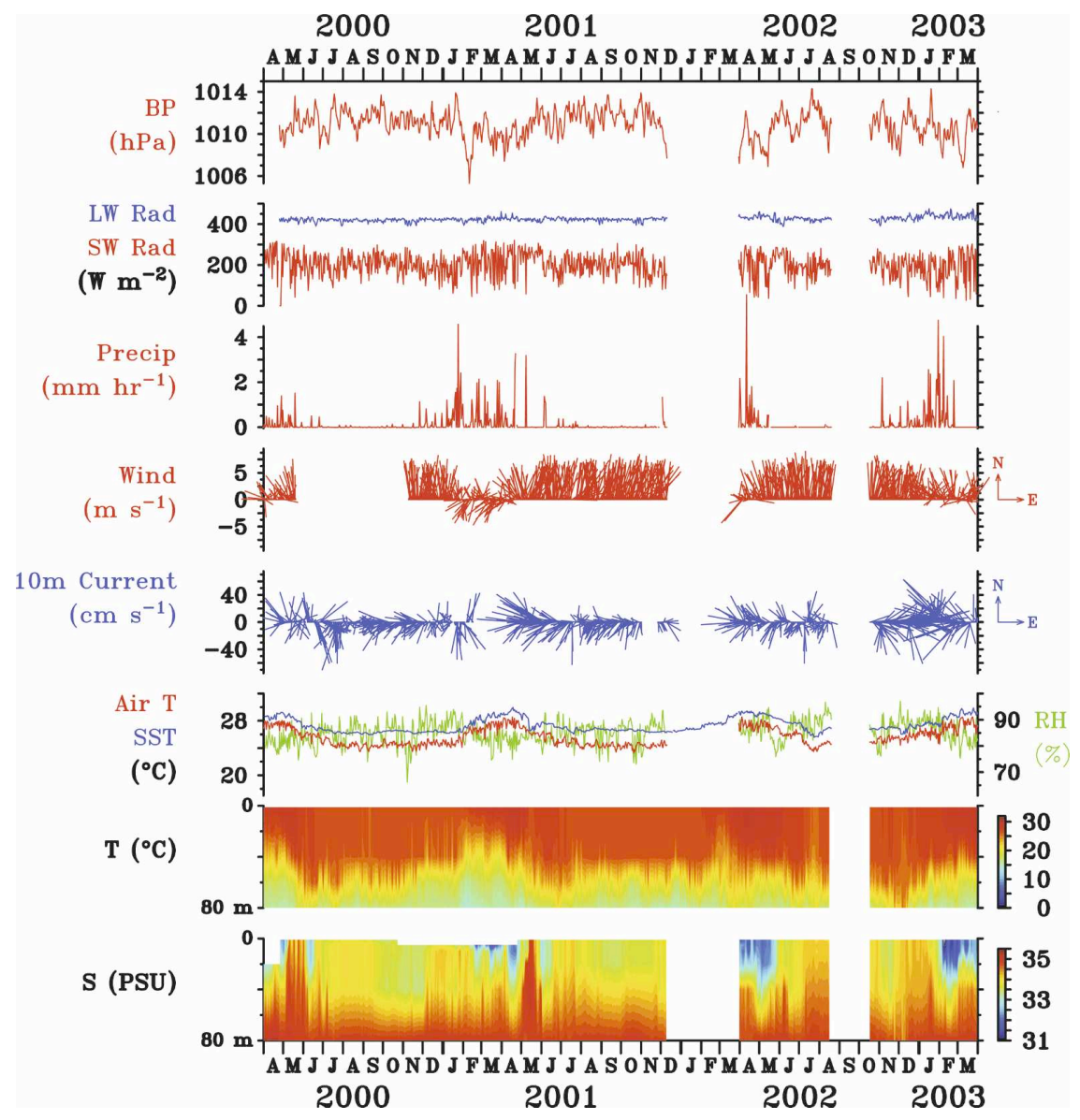

FIG. 2. Daily moored buoy time series at $3.5^{\circ} \mathrm{N}, 95^{\circ} \mathrm{W}$.

OSCAR zonal velocities are generally more reliable than meridional velocities near the equator (Bonjean and Lagerloef 2002). Monthly mean differences between TAO and OSCAR currents are $\sim 5-10 \mathrm{~cm} \mathrm{~s}^{-1}$.

\section{Description of the mean, seasonal, and interannual variations}

\section{a. Annual means}

Mean conditions in the eastern Pacific over the 3-yr period April 2000-March 2003 show a significant hemispheric contrast in the ocean and atmosphere (Fig. 4). The southeast trade winds have a strong southerly component extending north of the equator where they converge with the northeast trade winds between $5^{\circ}$ and $8^{\circ} \mathrm{N}$. SST is lower and atmospheric pressure is higher in the Southern Hemisphere, while rainfall is highest in the ITCZ north of the equator. The SST minimum in the cold tongue is shifted upwind (i.e., south) of the equator (see also Figs. 5 and 6 ) and is associated with a clear tendency for meridional velocity divergence, con- sistent with Ekman current dynamics in response to cross-equatorial winds, as first described by Cromwell (1953). The velocity at $10-\mathrm{m}$ depth also shows the classic meridional structure of currents in the eastern Pacific, namely, the westward flowing South Equatorial Current (SEC) between $8^{\circ} \mathrm{S}$ and $4^{\circ} \mathrm{N}$, the North Equatorial Current (NEC) between $8^{\circ}$ and $12^{\circ} \mathrm{N}$, and the eastward North Equatorial Countercurrent (NECC) centered at $5^{\circ} \mathrm{N}$. The data also show the highest SEC speeds at $2^{\circ} \mathrm{N}$, consistent with ship drift and drifter climatologies (Reverdin et al. 1994).

The mean subsurface temperature structure (Fig. 5) shows isotherms immediately below the surface bowing upward in the region of meridional divergence between $0^{\circ}$ and $2^{\circ} \mathrm{S}$, indicative of mean upwelling (Fig. 5). There is also depression of the thermocline near $4^{\circ} \mathrm{N}$, just poleward of the sharp SST front. In addition, there is ridging of isotherms near $8^{\circ} \mathrm{N}$ associated with the NECC and a slight weakening of the vertical gradient near the equator between 60 and $100 \mathrm{~m}$ associated with the presence of the eastward flowing Equatorial Undercurrent (EUC). Salinity exhibits a surface minimum 

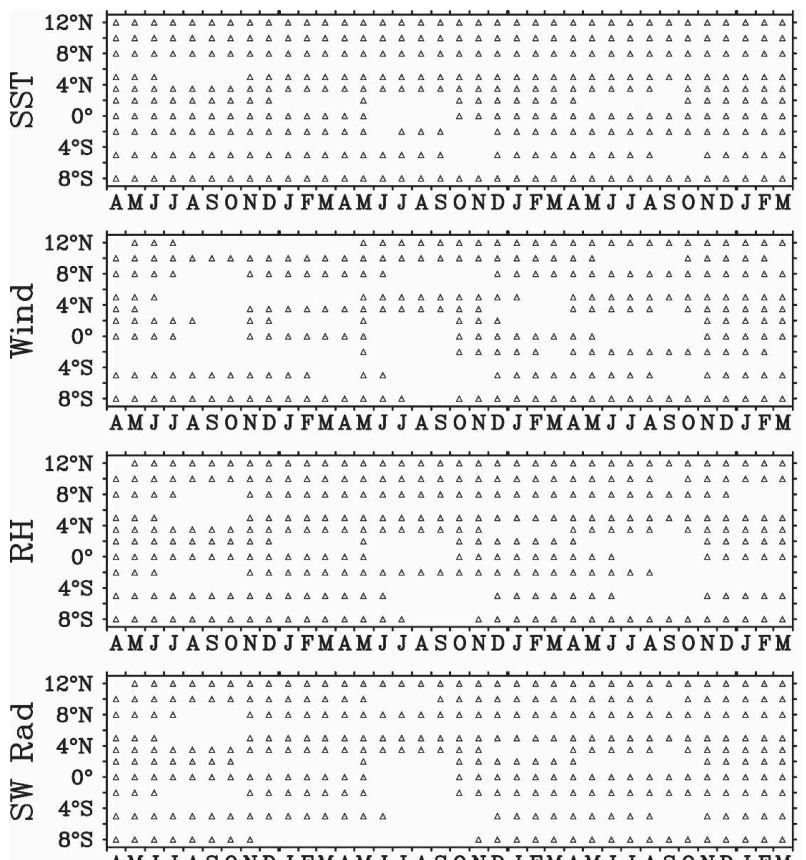

AMJJASONDJFMAM J JASONDJFMAM J JASONDJFM
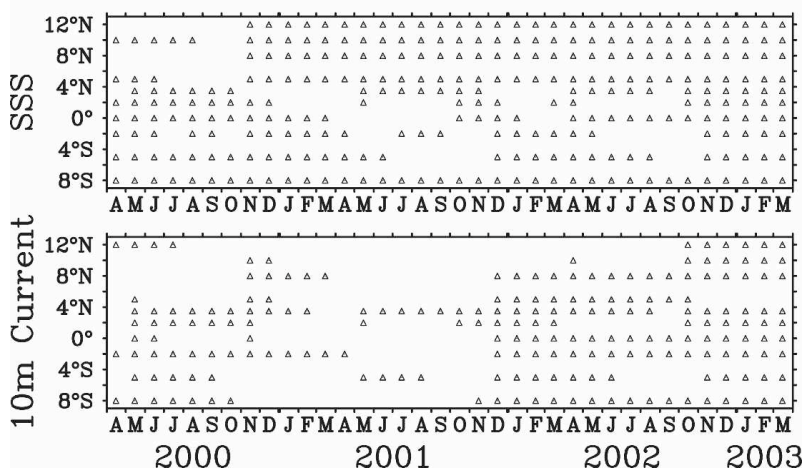

FIG. 3. Data return by month for selected time series along $95^{\circ} \mathrm{W}$. A value is indicated if at least 15 days of data are available within a given month.

in the vicinity of the ITCZ, where rain rates are highest, and a subsurface maximum in the Southern Hemisphere, associated with the equatorward penetration of the Southern Subtropical Mode Waters. Density is controlled mainly by temperature except near the salinity minimum below the ITCZ. Relative to longitudes farther to the west, the hydrographic structure along $95^{\circ} \mathrm{W}$ is very shallow because of the zonal tilt of the thermocline and pycnocline in response to mean easterly trade wind forcing (Johnson et al. 2002; Zhang and McPhaden 2006).

We define mixed layer depth (MLD) as the depth at which temperature is $0.5^{\circ} \mathrm{C}$ below SST using daily averaged data. The mean MLD ranges between 15 and $40 \mathrm{~m}$ along $95^{\circ} \mathrm{W}$ and generally follows the depth of the mean thermocline (Fig. 5). The MLD is shallowest in
TABLE 1. Data return (\%) by variable along $95^{\circ} \mathrm{W}$ for April 2000-March 2003. $T(z), S(z)$, and $V(z)$ represent temperature, salinity, and velocity, respectively, below 1-m depth.

\begin{tabular}{|c|c|c|c|}
\hline \multicolumn{4}{|c|}{ TAO/EPIC data return, April 2000-March 2003} \\
\hline Air temperature & 85.8 & Wind & 70.1 \\
\hline Relative humidity & 82.6 & SST & 89.5 \\
\hline Surface salinity & 77.1 & $T(z)$ & 84.8 \\
\hline Shortwave radiation & 81.4 & $S(z)$ & 76.1 \\
\hline Longwave radiation & 80.7 & $U(z)$ & 40.3 \\
\hline Rain & 74.4 & & \\
\hline Barometric pressure & 84.8 & \multirow{2}{*}{\multicolumn{2}{|c|}{79.4}} \\
\hline Average & & & \\
\hline
\end{tabular}

the upwelling zone near the equator and near $8^{\circ} \mathrm{N}$ in the vicinity of the NECC ridge; it is deepest on average near $4^{\circ} \mathrm{N}$ and $8^{\circ} \mathrm{S}$. An alternative definition of MLD in terms of a $0.125 \mathrm{~kg} \mathrm{~m}^{-3}$ density increase from the surface yields results that typically differ on average by $\leq 5 \mathrm{~m}$, except between $3.5^{\circ}$ and $5^{\circ} \mathrm{N}$ in the ITCZ where an $\sim 10$-m-thick barrier layer is found (Fig. 5). At most latitudes the two definitions are essentially identical, given uncertainties in our MLD calculations (see appendix), while under the ITCZ our conclusions would not fundamentally change using a definition based on density. Moreover, barrier layers are generally thin in the eastern Pacific except during major El Niños (Ando and McPhaden 1997; Cronin and Kessler 2002). Thus, we prefer a definition of MLD based on temperature since more data are available for temperature than for temperature and salinity combined, which results in fewer data gaps for MLD time series defined by temperature rather than by density.

\section{b. Seasonal and interannual variations}

Variability about the mean exhibits a well-defined seasonal cycle. For sea surface temperature, each of the three years shows development of the equatorial cold tongue in boreal summer and fall with warming in the late boreal winter and spring (Fig. 6a). South of the equator, the seasonality is similar, though delayed relative to the equator by about $1-2$ months. To the north, the warm season shifts toward May-August and the cool season toward November-January. Variations exhibit a strong hemispheric asymmetry in amplitude, with largest standard deviations $\left(\sim 2^{\circ}-3^{\circ} \mathrm{C}\right)$ in the upwelling zone near to and south of the equator, and smallest standard deviations north of the equator.

Compared to seasonal variations in SST near the equator, interannual variability along $95^{\circ} \mathrm{W}$ during this period is relatively weak (cf. Figs. $6 \mathrm{~b}$ and $6 \mathrm{c}$ ). The largest temperature anomalies of $\sim 1^{\circ}-1.5^{\circ} \mathrm{C}$ in late 2002 are associated with a moderate intensity El Niño 

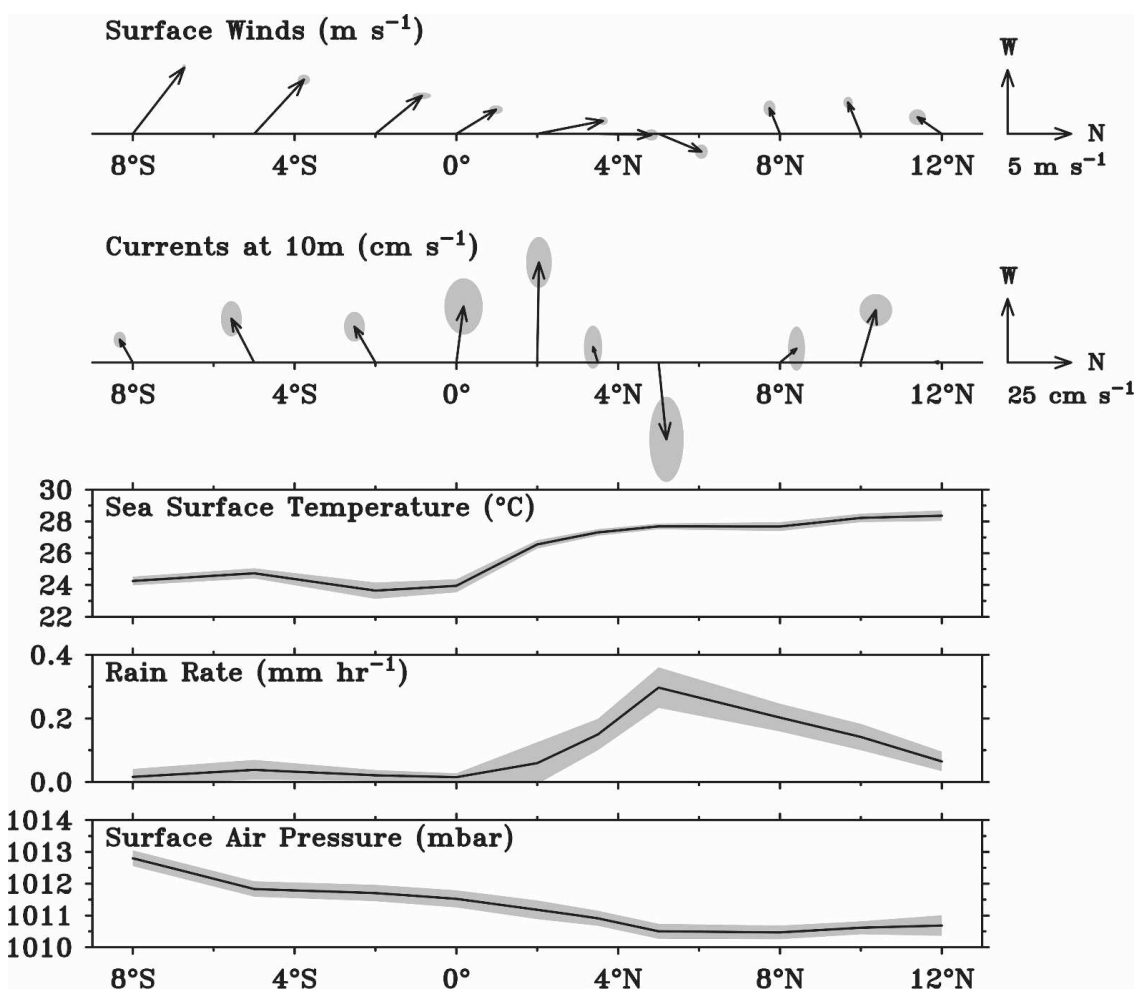

FIG. 4. Mean surface winds, 10-m currents, SST, rainfall, and barometric pressure between $8^{\circ} \mathrm{S}$ and $12^{\circ} \mathrm{N}$ along $95^{\circ} \mathrm{W}$ from TAO mooring data for 1 Apr 2000 to 31 Mar 2003. Shading indicates one standard error for the mean based on sampling errors that result from interannual variations in the data. Data were insufficient to compute a standard error for the nearzero velocity at $12^{\circ} \mathrm{N}$.

(McPhaden 2004), and $0.5^{\circ} \mathrm{C}$ cool anomalies in 2000-01 are associated with weak La Niña conditions. Thus, the mean seasonal cycle formed from these three years of data is a reasonable representation of the seasonal cycle computed over longer records-as, for example, from the 25-yr (1982-2006) Reynolds et al. (2002) SST analysis (cf. Figs. 7a and 7b). Using TMI instead of TAO SST data for April 2000-March 2003 reveals the same basic features evident in TAO and Reynolds SSTs, but TMI defines the southward shift of the near-equatorial minimum SST more sharply owing to higher spatial resolution of this satellite product (cf. Figs. 7a-c). We will thus use TMI SSTs to compute spatial gradients of SST to estimate horizontal advection in the following section, but TAO temperatures for computations involving local heat content variations.

Variations in mixed layer depth, like SST, have a well-defined seasonal cycle, although the relationship of MLD to SST is very different on seasonal versus interannual time scales (Fig. 8). On interannual time scales, an unusually deep mixed layer is associated with warm SST, while an unusually shallow mixed layer is associated with cold SST. Both are highly correlated with thermocline depth as inferred from variations in the depth of the $20^{\circ} \mathrm{C}$ isotherm (cf. Figs. $6 \mathrm{c}$ and $8 \mathrm{c}, \mathrm{d}$ ). These relationships reflect the dominance of remote forcing on eastern Pacific subsurface thermal structure and SST associated with El Niño and La Niña (Zhang and McPhaden 2006). In contrast, the relationship of MLD and thermocline depth to SST is more complicated for the mean seasonal cycle. For example, there is a tendency for MLD and thermocline depth to be anticorrelated with SST at some latitudes (e.g., $4^{\circ} \mathrm{N}$ and $8^{\circ} \mathrm{S}$ ) where a deep mixed layer and thermocline are associated with cold rather than warm SSTs (see also Hayes et al. 1991). This complicated relationship between subsurface thermal structure and SST suggests that local ocean-atmosphere interactions, which are particularly effective at changing SST in regions of a shallow mean thermocline, are likely to be important in controlling the mixed layer temperature balance on seasonal time scales in the eastern tropical Pacific (Xie 1994; Li and Philander 1996; Fedorov and Philander 2000).

Surface currents in the tropical Pacific are characterized by alternating zonal flows in the NEC, NECC, and 

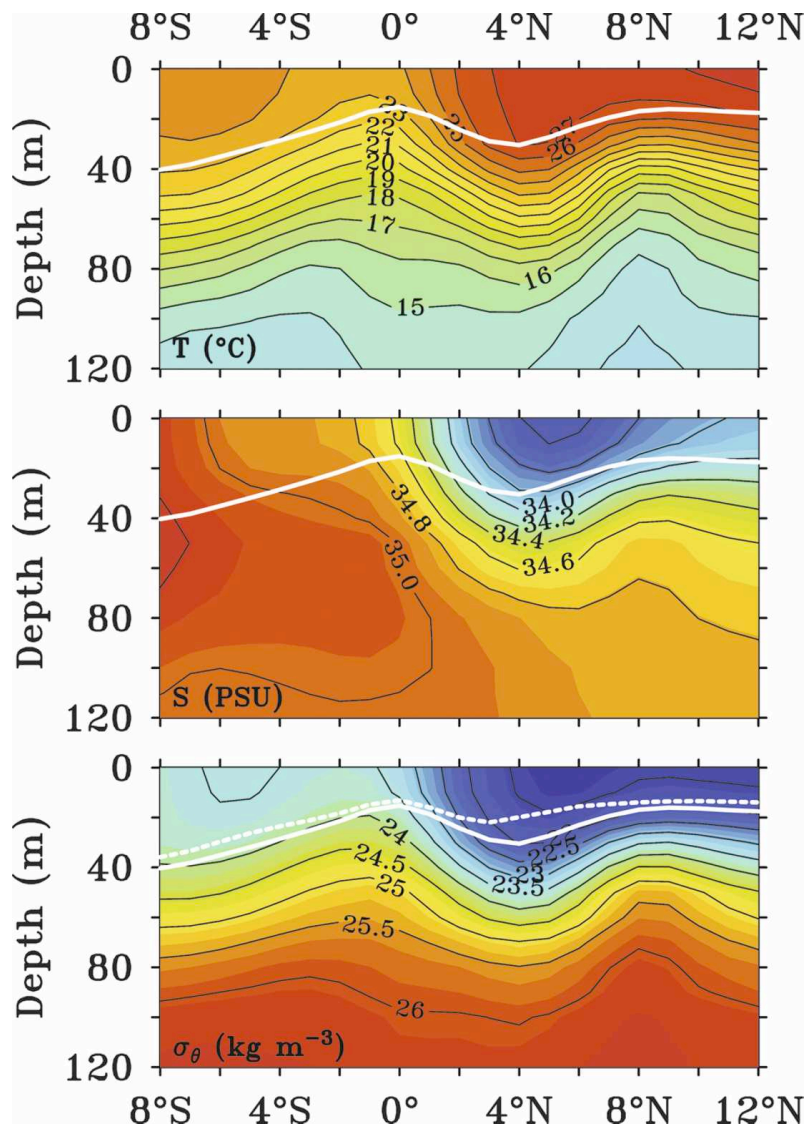

FIG. 5. Mean temperature, salinity, and density structure in the upper $120 \mathrm{~m}$ from TAO mooring data, April 2000-March 2003. The mean mixed layer depth, defined as the depth at which temperature drops below SST by $0.5^{\circ} \mathrm{C}$, is overplotted as a solid white line in each graph. The dashed white line on the density plot is mixed layer depth, defined as the depth at which density increases by $0.125 \mathrm{~kg} \mathrm{~m}^{-3}$ from the surface. The two definitions are essentially identical, except between $3.5^{\circ}$ and $5^{\circ} \mathrm{N}$ where a $\sim 10$-m-thick barrier layer is evident. Mixed layer depths were calculated first from daily data, then averaged to long-term means.

SEC (Fig. 4). TAO velocity data at a depth of $10 \mathrm{~m}$ in the mixed layer capture aspects of the seasonality of the currents in portions of the record that are not too gappy (Fig. 9a), revealing, for example, the tendency for a reduction in the NECC in boreal spring and a stronger SEC in boreal summer. There is also a boreal springtime reversal of the SEC on the equator, in agreement with previous studies of the circulation in the tropical Pacific (e.g., Halpern 1987; Taft and Kessler 1991; Reverdin et al. 1994; Yu and McPhaden 1999). This reversal extends farther south than north between $2^{\circ} \mathrm{N}-$ $2^{\circ} \mathrm{S}$. There is evidence of intensified meridional divergence near the equator in late boreal spring (Fig. 10a), coincident with rapidly cooling temperatures in the equatorial cold tongue that one would expect to be related to equatorial upwelling (Fig. 7). These circula- tion features and their variations are also observed in the more complete $15-\mathrm{m}$ depth OSCAR velocities (Figs. $9 \mathrm{~b}$ and $10 \mathrm{~b}$ ). The mean and standard deviation of differences between TAO and OSCAR are typically $\sim 5-10 \mathrm{~cm} \mathrm{~s}^{-1}$ and sometimes larger (Figs. 9c and 10c), most likely due to a combination of sampling errors, OSCAR analysis errors, and TAO instrumental errors. The 5-m difference in nominal depths of the two velocity estimates probably accounts for only a small fraction of the observed differences since vertical shears in the mixed layer are in general relatively weak (see below).

\section{Mixed layer heat balance analysis}

\section{a. Mixed layer temperature balance diagnostic equation}

In this section, we will examine the mixed layer temperature balance so as to understand the processes affecting SST. Mixed layer temperature $(T)$ should be nearly identical to SST if temperature is vertically uniform in the surface mixed layer. As a measure of this uniformity, we compared SST to $T$ averaged over a space and timevarying mixed layer of thickness $h$ for the 3-yr period April 2000-March 2003. SST was $0.1^{\circ} \mathrm{C}$ warmer on average than $T$, with a rms difference between the two of $\sim 0.1^{\circ}-0.2^{\circ} \mathrm{C}$ and a correlation of $>0.95$ across $12^{\circ} \mathrm{N}-8^{\circ} \mathrm{S}$. Taking time derivatives of $T$ and SST further eliminates the systematic $0.1^{\circ} \mathrm{C}$ difference between the two, so they can be considered equivalent without loss of generality in the mixed layer temperature balance equation, given by

$$
\frac{\partial T}{\partial t}=-\mathbf{v} \cdot \boldsymbol{\nabla} T-\frac{H \Delta T w_{e}}{h}+\frac{q_{0}+q_{-h}}{\rho c_{p} h}-F .
$$

This expression is based on the formalism described in McPhaden (1982) and Moisan and Niiler (1998), where the density of seawater $\left(\rho=1022.4 \mathrm{~kg} \mathrm{~m}^{-3}\right)$ and heat capacity $\left(c_{p}=3940 \mathrm{~J} \mathrm{~kg}^{-1}{ }^{\circ} \mathrm{C}^{-1}\right)$ are constant. All surface flux terms are treated as positive when they represent gains to the mixed layer.

The temperature tendency term is represented by $T_{t}$. Horizontal heat advection $(\mathbf{v} \cdot \boldsymbol{\nabla} T)$ can be decomposed into zonal $\left(u T_{x}\right)$ and meridional $\left(v T_{y}\right)$ components, assuming that both temperature and velocity are vertically homogenous in the mixed layer. Consistent with this assumption, the shear between 10 and $40 \mathrm{~m}$ from the TAO velocity data between $5^{\circ} \mathrm{N}$ and $5^{\circ} \mathrm{S}$ is generally weak: in most cases $u$ and $v$ at $40 \mathrm{~m}$ are in the same direction and of similar magnitude to the currents at $10 \mathrm{~m}$. Where shears are substantial between 10 and $40 \mathrm{~m}\left(0^{\circ}\right.$ and $\left.2^{\circ} \mathrm{S}\right)$, the mixed layer is much shallower than $40 \mathrm{~m}$ (Figs. 5 and 8), so flow at 10-15-m 
(a)
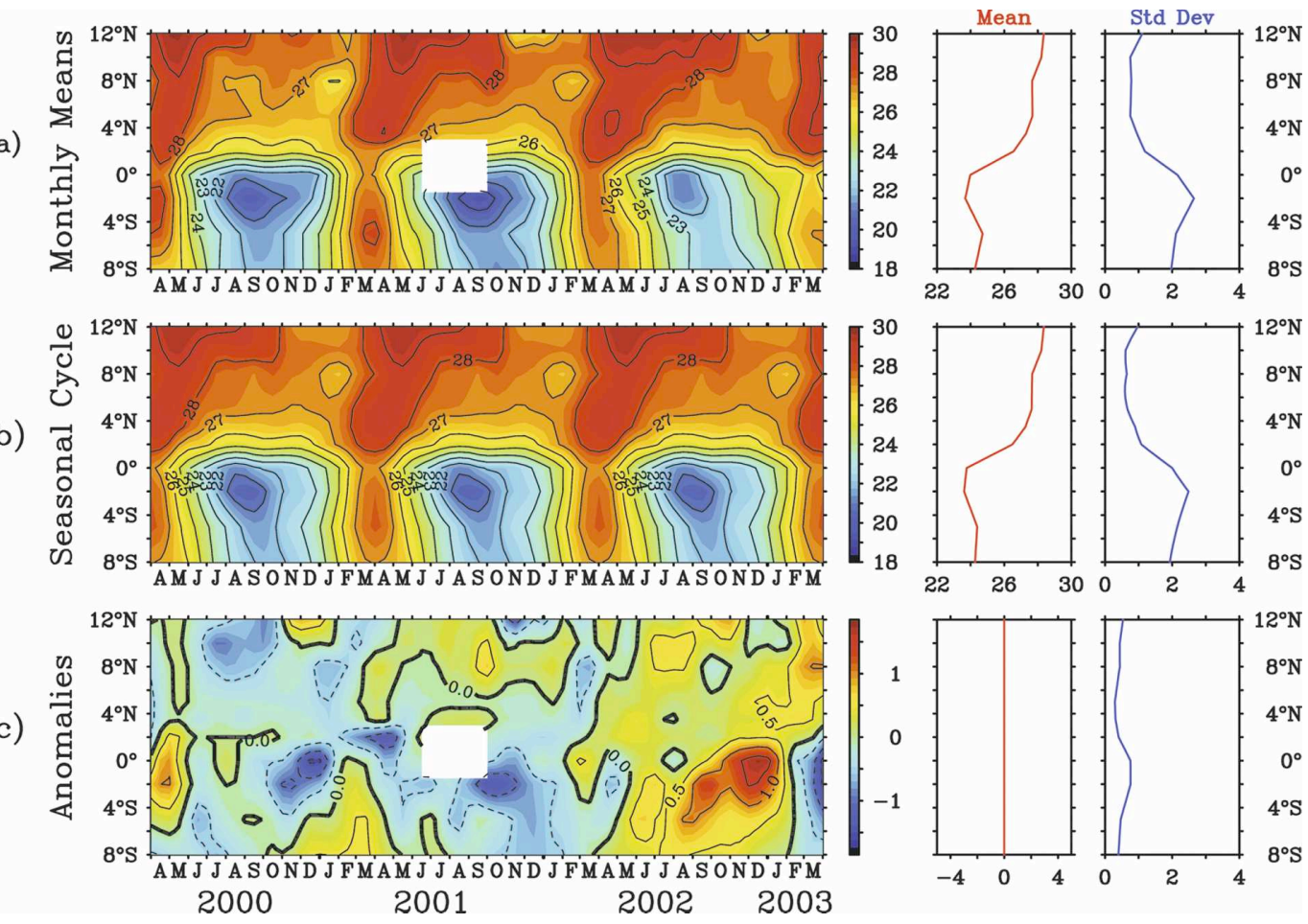

FIG. 6. TAO SST (in ${ }^{\circ} \mathrm{C}$ ) along $95^{\circ} \mathrm{W}$ for (a) monthly means from April 2000 to March 2003, (b) the mean seasonal cycle repeated for $3 \mathrm{yr}$, and (c) interannual anomalies based on the differences between (a) and (b). Right-hand side shows annual means and std devs.

(a)
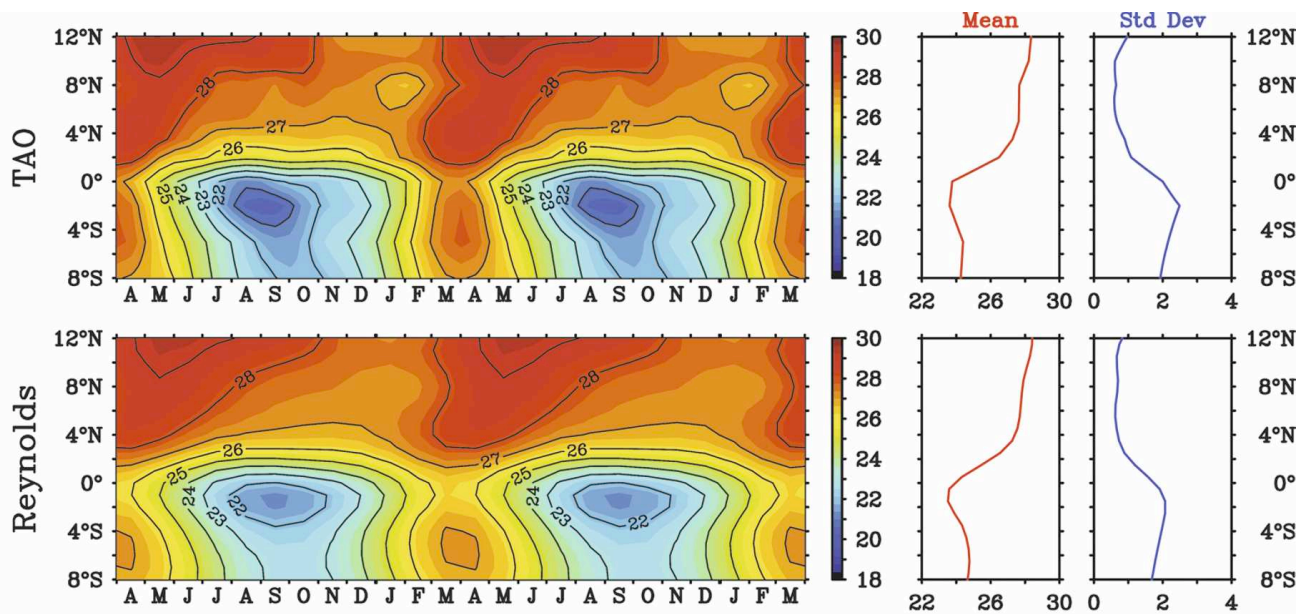

(b)
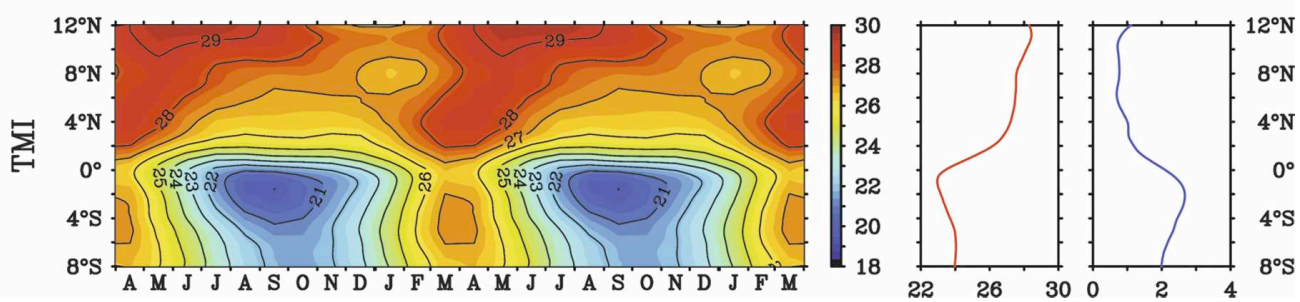

FIG. 7. Mean seasonal cycle of SST (in ${ }^{\circ} \mathrm{C}$ ) repeated for 2 yr from (a) TAO data, (b) the Reynolds et al. (2002) analysis, and (c) TMI data. TAO and TMI seasonal cycles are based on 3 yr of data from April 2000 to March 2003; the Reynolds seasonal cycle is based on $25 \mathrm{yr}$ of data from 1982 to 2006. The right-hand side shows annual means and std devs. 
(a)
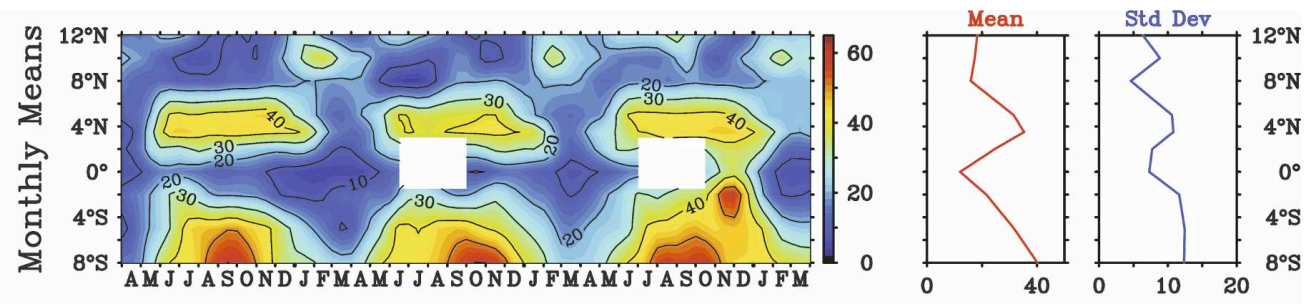

(b)
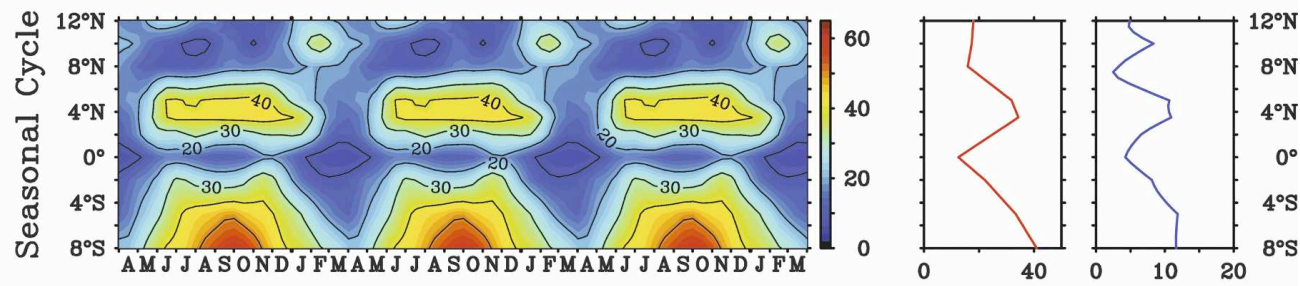

(c)
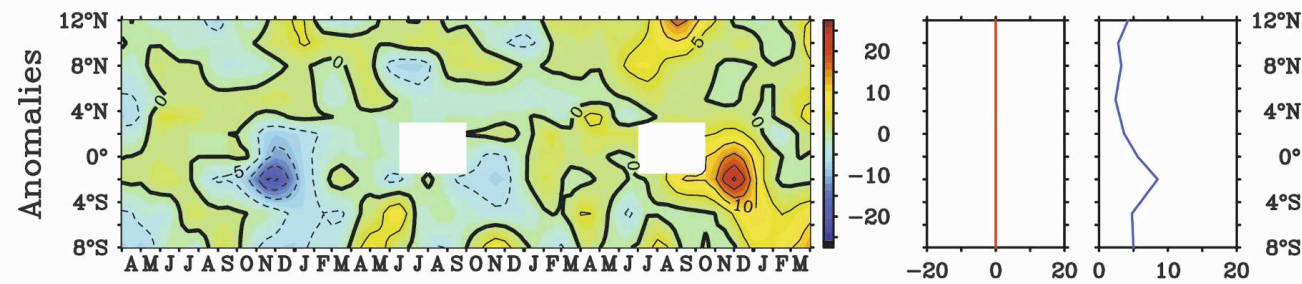

(d)

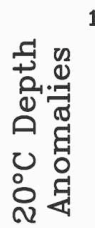

$12^{\circ} \mathrm{N}$
$8^{\circ} \mathrm{N}$
$4^{\circ} \mathrm{N}$
$0^{\circ}$
$4^{\circ} \mathrm{S}$
$8^{\circ}$
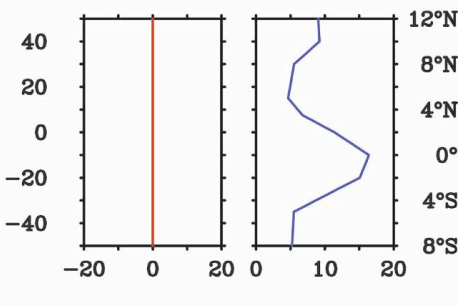

FIG. 8. Mixed layer depth from TAO data along $95^{\circ} \mathrm{W}$ for (a) monthly means from April 2000 to March 2003, (b) the mean seasonal cycle of mixed layer depth repeated for $3 \mathrm{yr}$, and (c) interannual anomalies based on the difference between (a) and (b). (d) Interannual anomalies in thermocline depth as indicated by the $20^{\circ} \mathrm{C}$ isotherm depth. In general, $20^{\circ} \mathrm{C}$ depth variations and MLD variations track each other closely on both mean seasonal and interannual time scales. The right-hand side shows annual means and std devs. Units are meters.

depth is still a reasonable representation of mixed layer currents. Thus, we neglect the covariance of departures in horizontal velocity and temperature from their vertical-averaged values in (1). These terms are generally thought to be of secondary importance in the equatorial Pacific (Cronin and McPhaden 1997; Swenson and Hansen 1999).

We utilize both TAO and OSCAR currents in the heat balance calculation, but favor OSCAR for presentation of results because OSCAR (i) qualitatively agrees with the mooring data in general, (ii) has no major gaps that complicate the analysis, and (iii) does not lead to fundamentally different results compared to using TAO data. In addition, OSCAR allows for computation of the two-dimensional horizontal divergence field because velocities extend not only latitudinally along $95^{\circ} \mathrm{W}$ but also east and west as well.
The net surface heat flux across the air-sea interface $\left(q_{0}\right)$ is composed of the net shortwave solar radiation $\left(q_{\mathrm{sw}}\right)$, net longwave radiation $\left(q_{\mathrm{lw}}\right)$, latent heat flux $\left(q_{\text {lat }}\right)$, and sensible heat flux $\left(q_{\text {sen }}\right)$. Here $q_{-\mathrm{h}}=$ $-0.45 q_{\mathrm{sw}} \exp (-\lambda h)$ is the heat loss by shortwave radiation that penetrates through the mixed layer with an extinction coefficient of $\lambda^{-1}=25 \mathrm{~m}$ (Paulson and Simpson 1977; Hayes et al. 1991). The combination of $q_{0}+$ $q_{-\mathrm{h}}$, represents the net surface heat flux absorbed by the mixed layer, which for simplicity we will refer to as the "adjusted net surface heat flux" $\left(q_{\text {adj }}\right)$. The penetrative component of radiation is estimated from daily data using observed mixed layer depths and incoming shortwave radiation. The $q_{0}$ computation was described in Cronin et al. (2006b). Briefly, turbulent surface heat fluxes were computed using the Tropical Ocean and Global Atmosphere Coupled Ocean-Atmosphere Response Experiment (TOGA COARE) v3.0 bulk formu- 
(a)
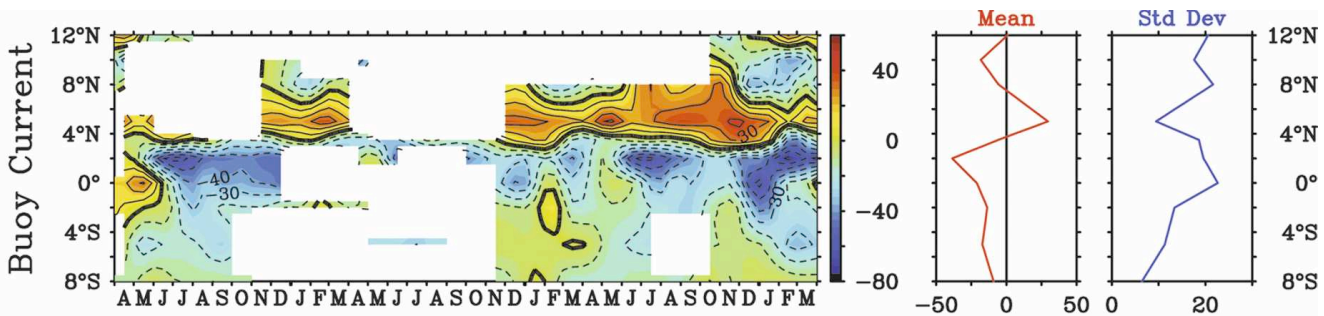

(b)
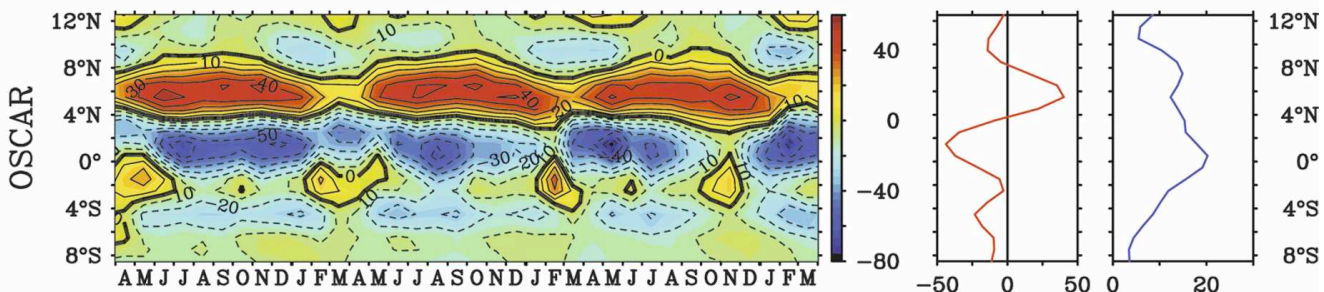

(c)
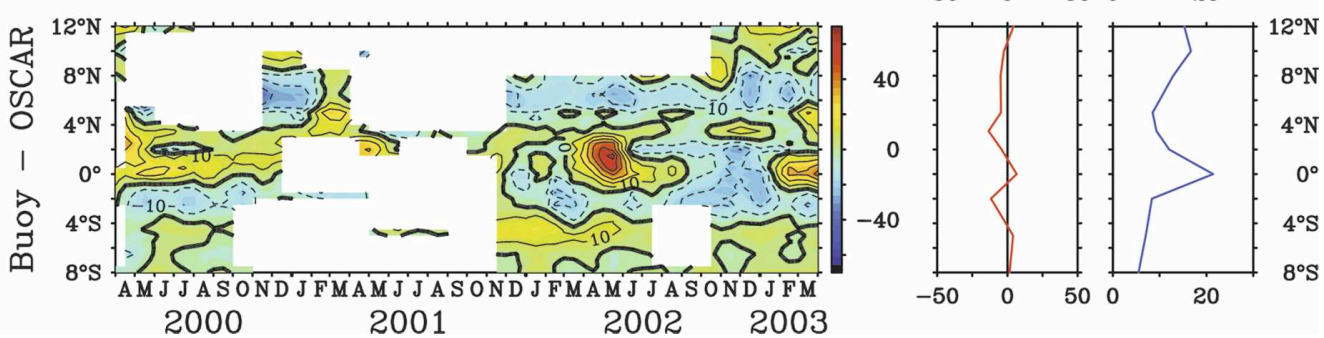

FIG. 9. Monthly mean zonal currents (in $\mathrm{cm} \mathrm{s}^{-1}$ ) along $95^{\circ} \mathrm{W}$ from April 2000 to March 2003 from (a) 10-m TAO velocities, (b) OSCAR analyses calibrated against drifting buoy velocities at $15 \mathrm{~m}$, and (c) TAO minus OSCAR. Right-hand side shows annual means and std devs.

(a)
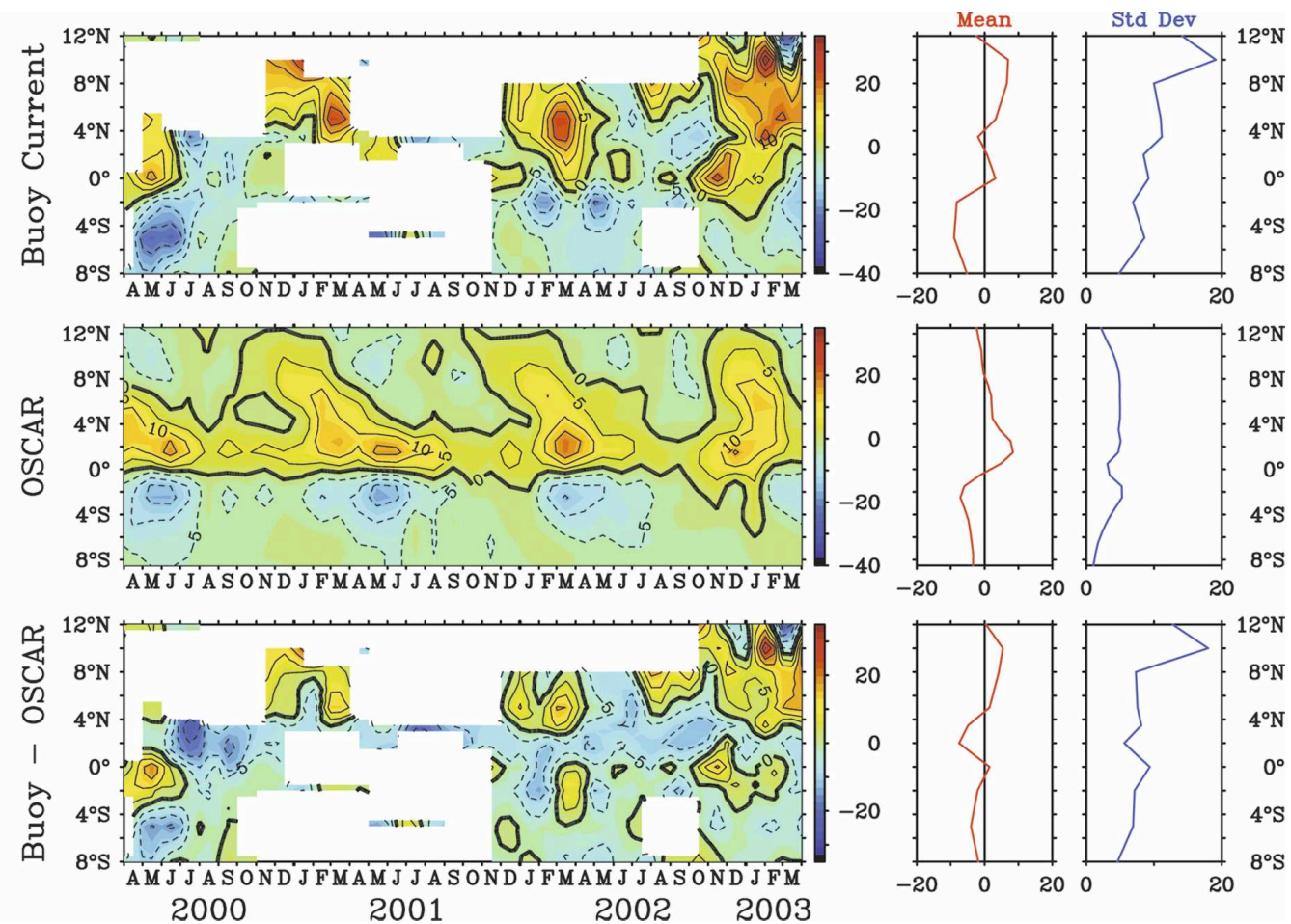

FIG. 10. Same as Fig. 9, but for monthly mean meridional currents. 
lae (Fairall et al. 2003). Hourly data were used when available to allow for estimates of cool skin and warm layer effects; otherwise, daily averaged data were used to compute these fluxes. Likewise, shortwave and longwave radiative fluxes were estimated using daily or, when available, hourly data. Shortwave irradiance was adjusted using a constant albedo of $5.5 \%$, and directly measured downwelling longwave radiation was adjusted for upwelling longwave radiation from the sea surface using observed SSTs.

Turbulent entrainment of cold thermocline water into the mixed layer is represented by $H w_{e} \Delta T / h$, where $w_{e}$ is entrainment velocity, $\Delta T$ is the difference between the temperature of entrained water and the mixed layer temperature, and $H$ is the Heaviside step function $(=1$ for $w_{e}>0$ and 0 for $\left.w_{e}<0\right)$. This formulation implies that entrainment can lead to mixed layer cooling, but not to warming. Other methods of defining $w_{e}$ are possible, some of which relax the constraint on zero detrainment warming. These different methods lead to quantitatively different results depending on the assumptions on which they are based (Kim et al. 2006), but they qualitatively agree in terms of magnitude and phasing. The term $F$ represents vertical turbulent diffusive flux out the base of the mixed layer.

We can readily estimate the temperature tendency, horizontal advection, and adjusted net surface heat flux from EPIC and other datasets. The entrainment and diffusive vertical flux terms cannot be directly estimated from our measurements without invoking model assumptions, so we will infer these from the residual of (1). The residual, however, also contains instrumental, computational, and sampling errors as well as the effects of other neglected physical processes. Thus, we must exercise caution when interpreting the residual, focusing only on the most robust aspects of its variability.

All terms in (1) are averaged to monthly means for each of the 36 months over the period April 2000March 2003. From these monthly values, we estimated a mean seasonal cycle. Error estimates for the various terms are described in the appendix.

\section{b. Surface heat flux}

The largest components of the surface flux are shortwave radiation and latent heat flux (Fig. 11), as found in previous studies of the tropical Pacific (e.g., Wang and McPhaden 1999, 2001; Cronin et al. 2006b). Clear-sky irradiance near the equator is dominated by a semiannual variation, but seasonality in cloudiness results in a dominant one cycle per year (cpy) variation in surface shortwave radiation (Fig. 11b). As shown by Cronin et al. (2006a), seasonal variations in cloud forcing are larger than the clear-sky variations at and north of $2^{\circ} \mathrm{S}$. Conversely, south of $2^{\circ} \mathrm{S}$ low clouds result in weaker cloud forcing; thus clear-sky variations dominate. Consequently, in the equatorial cold tongue, shortwave radiation is maximum in late boreal winter and spring when SST is warm and skies are relatively clear, while solar radiation is minimum in boreal summer when SSTs are cool and low clouds are prevalent (Kessler et al. 1998). Just north of the equator, elevated cloudiness during June-November over the SST frontal zone reduces insolation there (de Szoeke et al. 2005). At $8^{\circ} \mathrm{S}$, where a 1-cpy solar cycle in clear-sky solar radiation is more evident, shortwave radiation has an austral summer maximum and austral winter minimum. Shortwave radiation between $8^{\circ}$ and $12^{\circ} \mathrm{N}$ reflects meridional migration of high cloudiness in the ITCZ, which is closest to the equator in boreal spring and shifts northward in boreal summer and fall (Fig. 11a).

Latent heat flux (Fig. 11c) is suppressed over the equatorial cold tongue relative to neighboring latitudes because of the combination of relatively cold SSTs in boreal summer and weak wind speeds in boreal winter and spring (Fig. 11a). Conversely, latent heat fluxes are highest in magnitude just to the north of the equator from June to November due to advection of relatively cold dry air masses from the south passing over the SST frontal region. Destabilization of the air column in this frontal region also leads to local increases in wind speed (Fig. 11a) that enhance evaporation as southerly momentum is mixed down to the surface from aloft (Wallace et al. 1989; Chelton et al. 2001). At $8^{\circ} \mathrm{S}$, the increased evaporative cooling in austral winter is coincident with an increase in the intensity of the southeast trade winds.

There is a net surface heat flux into the ocean on average at all latitudes, although the ocean loses heat over the frontal region between $2^{\circ}-3.5^{\circ} \mathrm{N}$ from July to November because of elevated latent heat fluxes and reduced insolation (Fig. 11d). This frontal region therefore experiences a minimum average net heat gain (30 $\mathrm{W} \mathrm{m}^{-2}$ ) and high seasonal variability. Annual average net oceanic heat gain, on the other hand, is found just south of the equator at $2^{\circ} \mathrm{S}\left(150 \mathrm{~W} \mathrm{~m}^{-2}\right)$ in the equatorial cold tongue where evaporative flux is inhibited and insolation is greatest. The mean latitudinal gradient in net surface heat flux between extrema at these nearby latitudes is an impressive $120 \mathrm{~W} \mathrm{~m}^{-2}$, similar in magnitude to changes observed from EPIC aircraft measurements during boreal summer 2001 (de Szoeke et al. 2005).

The penetrative component of radiation is strongly modulated by the mixed layer depth. Radiative losses exceed $80 \mathrm{~W} \mathrm{~m}^{-2}$ near the equator in February-April 
(a)
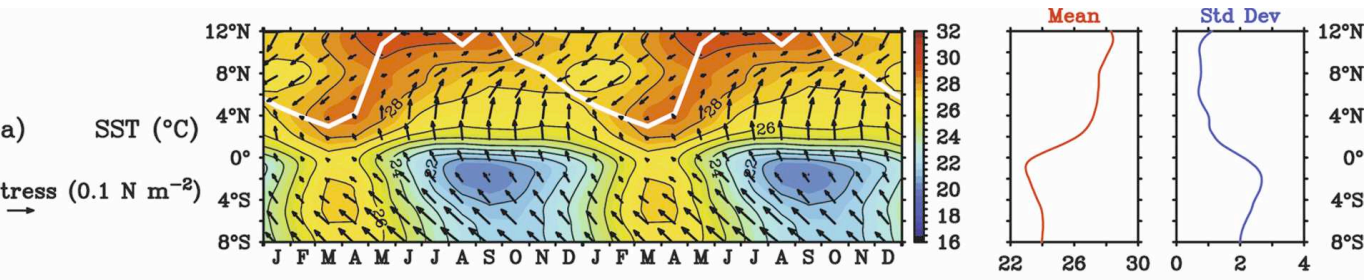

(b) $q_{s w}\left(w m^{-2}\right)$
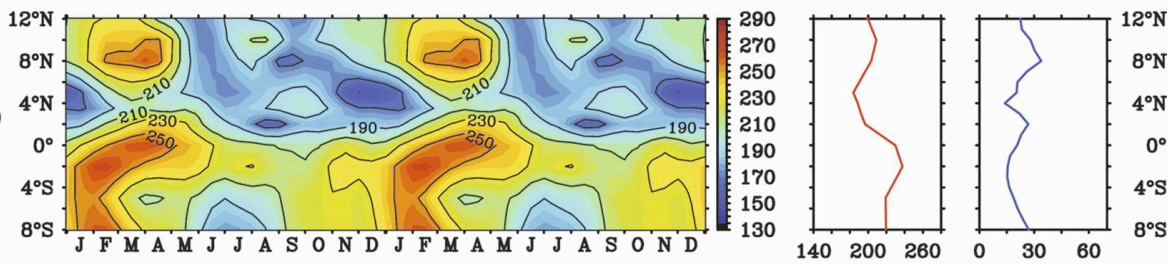

(c) $q_{\text {lat }}\left(\mathrm{W} \mathrm{m}^{-2}\right)$
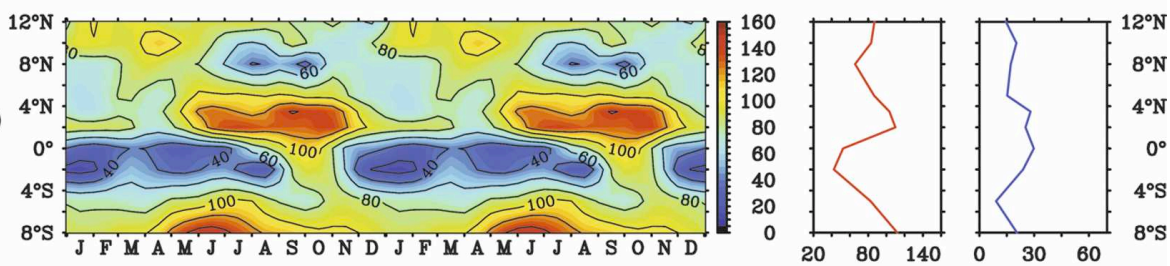

(d)
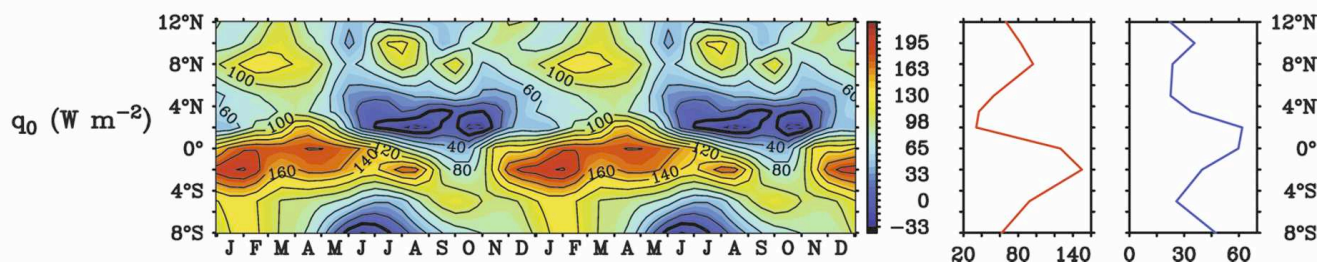

FIG. 11. Mean seasonal cycle, repeated for $2 \mathrm{yr}$ along $95^{\circ} \mathrm{W}$, of (a) wind stress from QuickSCAT superimposed on TMI SST, (b) shortwave radiation, (c) latent heat flux, and (d) net surface heat flux. The net surface heat flux takes into account both sensible and longwave radiation (not shown). The white line in (a) indicates the position of the ITCZ where the meridional component of the wind stress goes to zero. The right-hand side shows annual means and std devs, which in (a) are for SST only. Positive (negative) flux values indicate ocean heat gain (loss).

when the mixed layer is shallow. Conversely, minimum penetration (magnitude of less than $20 \mathrm{~W} \mathrm{~m}^{-2}$ ) occurs when the mixed layer depth is relatively deep, for example, near $4^{\circ} \mathrm{N}$ and $8^{\circ} \mathrm{S}$ during the latter half of the year. Cooling due to sensible heat flux from precipitation is most evident in the ITCZ where monthly means are typically $\leq 1 \mathrm{~W} \mathrm{~m}^{-2}$ and never greater than $2 \mathrm{~W}$ $\mathrm{m}^{-2}$; it has therefore been neglected.

\section{c. One-dimensional (local) heat balance}

As a first step, we assume a local one-dimensional heat balance by neglecting horizontal advection (Fig. 12). The net adjusted surface heat flux, converted to a temperature tendency (i.e., $q_{\mathrm{adj}}^{\prime}=q_{\mathrm{adj}} / \rho c_{p} h$ ), displays many of the same features as the net surface heat flux (Fig. 12a). The pattern of the temperature tendency term $T_{t}$ is, however, very different than that of $q_{\text {adj }}^{\prime}$. Thus, the residual of the two terms (i.e., $q_{\mathrm{res}}^{\prime}=T_{t}$ $q_{\text {adj }}^{\prime}$ ) looks much like the negative of $q_{\text {adj }}^{\prime}$ except at the southern extreme of the section near $8^{\circ} \mathrm{S}$ where the amplitude and phase of $T_{t}$ and $q_{\text {adj }}^{\prime}$ are similar in magnitude (Fig. 13a). In other words, although variations in net adjusted surface heat flux warm and cool the surface layer, at most locations other processes must be important in affecting mixed layer temperature. The imbalance between the two terms is largest near the equator in boreal spring and between $8^{\circ}-10^{\circ} \mathrm{N}$ in boreal summer. The next section examines whether horizontal advection can account for these imbalances.

\section{d. Three-dimensional balance}

In this section, we extend the one-dimensional analysis to explicitly account for horizontal advection. SST gradients are computed from TMI satellite estimates using centered differences spanning $\pm 1^{\circ}$ in latitude and $\pm 2^{\circ}$ in longitude. In an attempt to preserve nonlinearity associated with tropical instability waves (TIWs), advection was computed from the 5-day OSCAR data and 
(a)
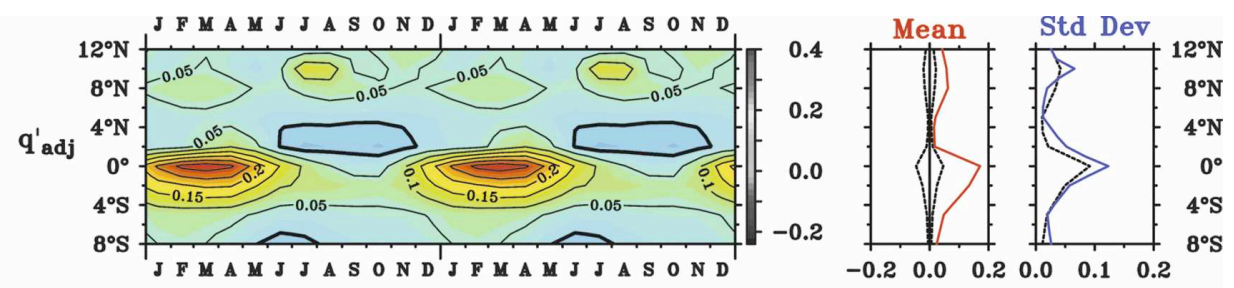

(b)
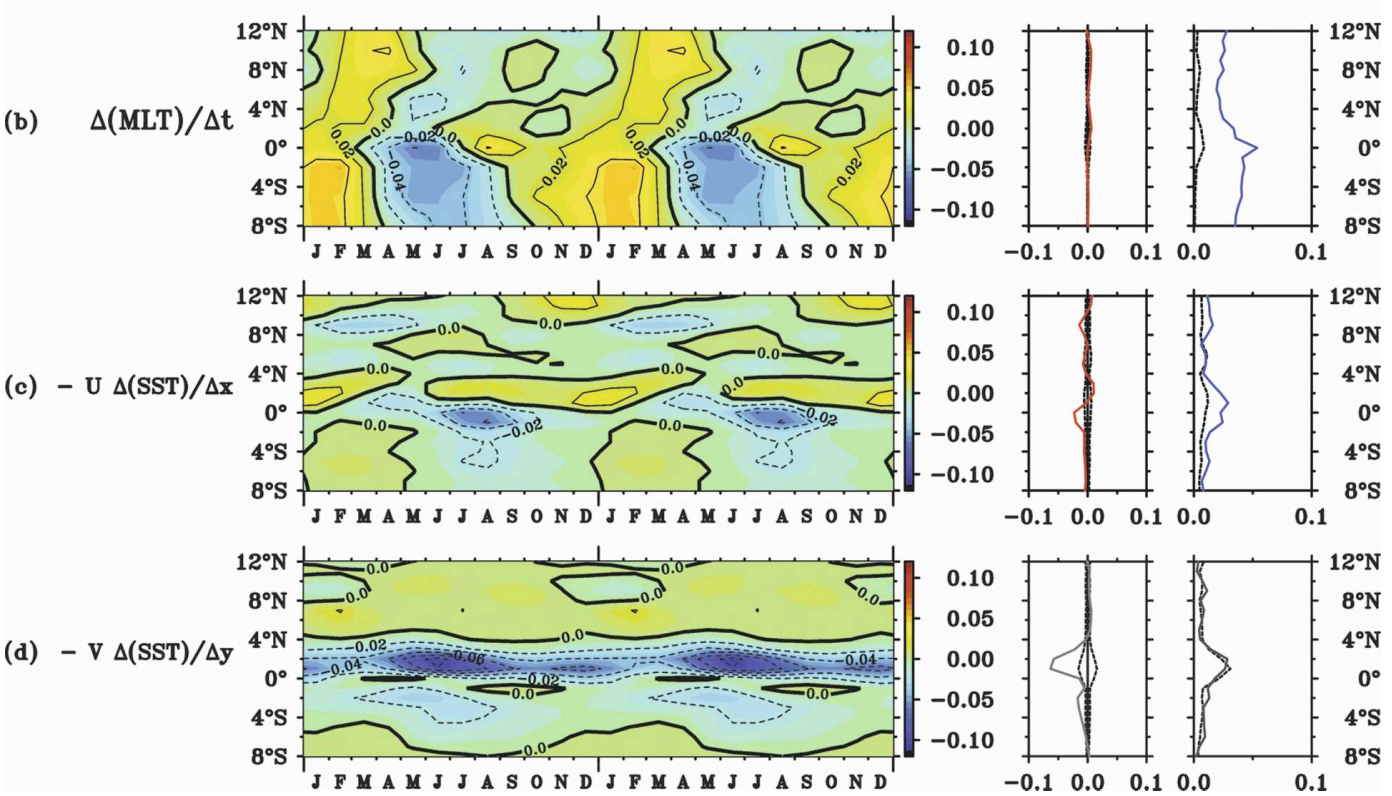

Fig. 12. Mean seasonal cycle, repeated for 2 yr along $95^{\circ} \mathrm{W}$, of (a) temperature equivalent of adjusted net surface heat flux $\left(q_{\mathrm{adj}}^{\prime}\right)$, (b) mixed layer temperature tendency, (c) zonal advection, and (d) meridional advection. Advection is defined as $-\mathbf{v} \cdot \boldsymbol{\nabla} T$ so that warming tendencies are positive and cooling tendencies negative. Dashed lines in right-hand side panels indicate one standard error for means and variations. Units are ${ }^{\circ} \mathrm{C}$ day $^{-1}$. Note the different contour intervals and scales in (a) vs (b)-(d).

5-day averaged TMI data, then averaged to monthly values. Mean seasonal cycles were calculated from these monthly values. We did the same computations with TAO velocity data. Neither calculation fully cap- tures the eddy temperature fluxes associated with TIWs, however. The OSCAR calculation falls short because, as noted above, the effective resolution of the velocity analysis is 10 days, which reduces much of the

(a) $\Delta(\mathrm{MLT}) / \Delta \mathrm{t}-\mathrm{q}_{\text {adj }}^{\prime}$
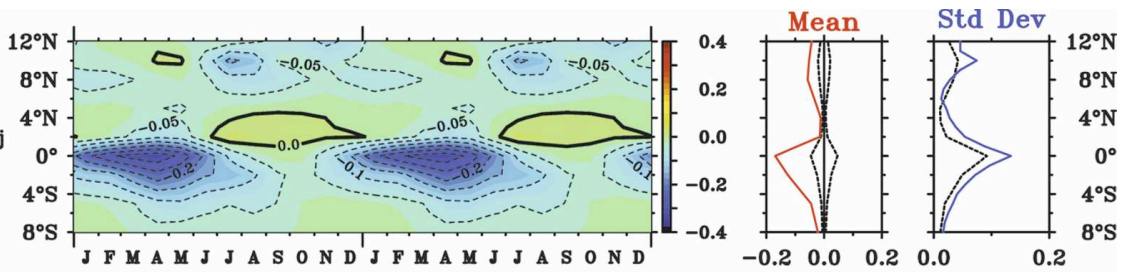

(b)

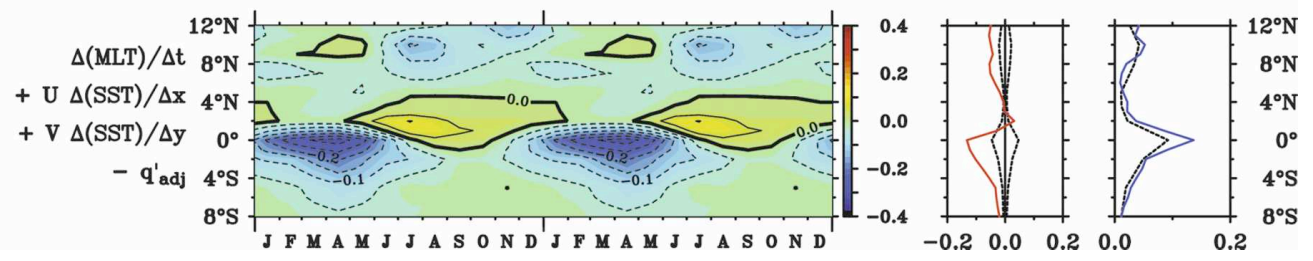

FIG. 13. Mean seasonal cycle, repeated for two years along $95^{\circ} \mathrm{W}$, of residuals $\left(q_{\mathrm{res}}^{\prime}\right)$ for the (a) one-dimensional and (b) three-dimensional mixed layer temperature balance. Dashed lines in right-hand side panels indicate one standard error for means and variations. Units are ${ }^{\circ} \mathrm{C}$ day ${ }^{-1}$. 
20-30-day TIW energy. The TAO calculation underestimates eddy fluxes because the gappy velocity records miss periods of energetic TIWs. This shortcoming in the calculation of advection affects our interpretation of the heat balance, as will be discussed later.

Zonal and meridional advection show highly structured variability in latitude (Fig. 12). Between $0^{\circ}$ and $4^{\circ} \mathrm{S}$, the seasonal cycle of zonal advection (Fig. 12c) is related to the boreal springtime reversal of the SEC and its westward intensification in summer, both acting on a negative SST gradient (i.e., SST decreasing to the east, as evident in Fig. 1). The phasing of zonal advection between $5^{\circ}$ and $8^{\circ} \mathrm{S}$ is similar to that near the equator, but of smaller amplitude. Just north of the equator where the mean SST gradient is positive on average (Fig. 1), westward flow in the SEC generally leads to warming. Between $8^{\circ}$ and $10^{\circ} \mathrm{N}$, seasonal intensification of both the westward flowing NEC and a negative zonal SST gradient produces maximum cooling by zonal advection in the early part of the calendar year.

The most distinctive feature in the meridional direction is the cooling that results between $3^{\circ} \mathrm{N}$ and $5^{\circ} \mathrm{S}$ from seasonally varying divergent currents straddling the equator (Figs. 10b and 12d). Cooling is stronger north of the equator than south because of the strong meridional SST gradient in the frontal region north of the cold tongue. However, the relatively sharp convergence of meridional flow at the northern flank of the cold tongue (Figs. 10a,b) limits the spread of the cold upwelled water to a narrower range of latitudes in the Northern vis à vis Southern Hemisphere.

In general, variations in horizontal advection are comparable to, or smaller than, those for the temperature tendency and the surface heat flux terms. Hence, the residual computed for the three-dimensional balance with horizontal advection (i.e., $q_{\mathrm{res}}^{\prime}=T_{t}+\mathbf{v} \cdot \boldsymbol{\nabla} T-$ $\left.q_{\text {adj }} / \rho c_{p} h\right)$ (Fig. 13b) looks very similar to that computed for the local balance (Fig. 13a). The most significant differences between the two are found just north of the equator where the magnitude and duration of the positive residual expands.

\section{Interpretation of residuals}

The residual of the three-dimensional temperature balance (Fig. 13b) reflects physical processes not explicitly accounted for as well as computational, instrumental, and sampling error. At those latitudes where the residual rises significantly above the estimated noise level, we can interpret the residual in terms of missing physics. Previous heat balance studies in the tropical Pacific have shown that turbulent mixing extracts heat from the mixed layer, particularly in regions where the mean mixed layer is thin with limited capacity to store heat (Chang 1993). Along $95^{\circ} \mathrm{W}$, the largest negative residuals, which indicate a missing sink of heat, occur near the equator and along $8^{\circ}-12^{\circ} \mathrm{N}$ where the mean mixed layer is less than $20 \mathrm{~m}$ thick (cf. Figs. 5, 8, and $13 \mathrm{~b})$. Moreover, there is considerable turbulence generation by shear between the EUC and SEC in the upwelling zone near the equator (Wang and McPhaden 1999 and references therein). Hence, a logical place to start is by assuming that some of the observed residuals are the result of these missing vertical turbulent mixing processes.

The maximum implied cooling rate, interpreted in terms of vertical turbulent processes, is $-0.33^{\circ} \mathrm{C}$ day ${ }^{-1}$ in April on the equator. This residual is equivalent to $\sim 150 \mathrm{~W} \mathrm{~m}^{-2}$, which is comparable to that found at $0^{\circ}$, $110^{\circ} \mathrm{W}$ (also in April), using similar methods, by Wang and McPhaden (1999). The maximum residual occurs when the mixed layer is seasonally shallowest, which facilitates greater turbulent vertical heat exchange with the thermocline. A second region of large inferred cooling (about $0.1^{\circ}-0.15^{\circ} \mathrm{C}$ day ${ }^{-1}$ ) is found at $8^{\circ}-12^{\circ} \mathrm{N}$ in boreal summer and fall, again when the mixed layer is seasonally shallow (Fig. 8b). This cooling represents a heat loss of $\sim 70-100 \mathrm{~W} \mathrm{~m}^{-2}$ from the surface layer.

Our analysis methodology does not allow us to separate turbulent entrainment from vertical diffusion, but we can set upper bounds on entrainment rates and vertical diffusivity by assuming one or the other is dominant. Thus, interpreting the residual as entirely due to entrainment, we can estimate entrainment velocity from the residual as $w_{e}=-h q_{\mathrm{res}}^{\prime} / \Delta T$, where for $\Delta T$ we use the temperature difference between the mixed layer and $20 \mathrm{~m}$ below (McPhaden 1982; Hayes et al. 1991). Alternatively, interpreting the residual as entirely due to vertical diffusion, we can estimate diffusivity as $K=-h q_{\mathrm{res}}^{\prime} / T_{z}$, where $T_{z}$ is the vertical gradient immediately below the mixed layer. If we use the vertical temperature gradient averaged over $20 \mathrm{~m}$ below the mixed layer, then $K$ would scale as $20 \mathrm{mx} w_{e}$ (i.e., $1 \times 10^{-3} \mathrm{~cm} \mathrm{~s}^{-1}$ for $w_{e}$ would be equivalent to 2 $\mathrm{cm}^{2} \mathrm{~s}^{-1}$ for $K$ ). In either case, variations in time and space will by definition resemble those of the residual.

With this ambiguity between mixing processes in mind, we focus most of the discussion on entrainment velocity, selectively referring to eddy diffusivity at appropriate times. We further concentrate our analysis on three distinct regions climatologically, namely the cold tongue region between $5^{\circ} \mathrm{N}$ and $5^{\circ} \mathrm{S}$, the region to the north of that where seasonality associated with meridional migration of the ITCZ is large $\left(8^{\circ}-12^{\circ} \mathrm{N}\right)$, and the southern extreme of the section $\left(8^{\circ} \mathrm{S}\right)$ in the region of 
(a)
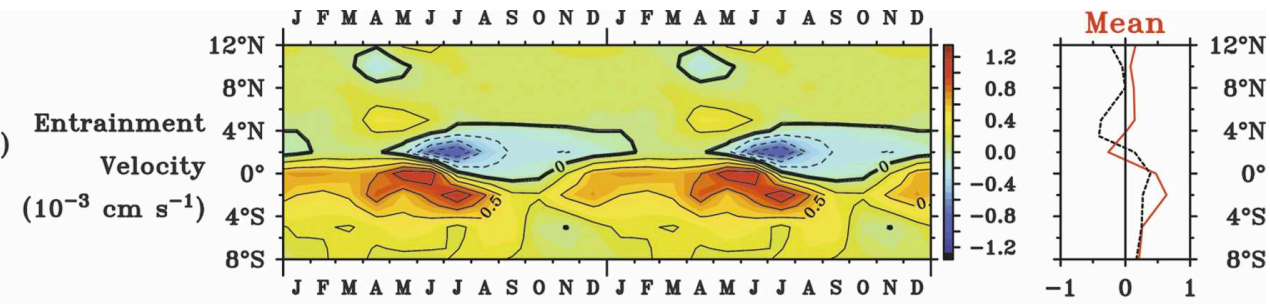

(b)
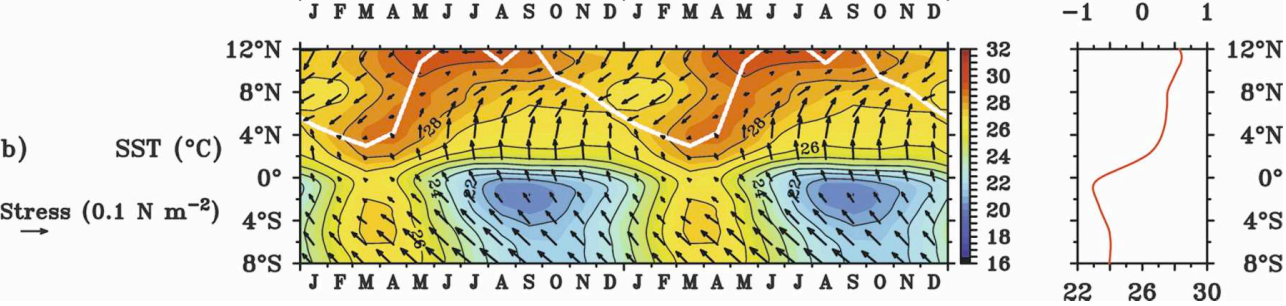

FIG. 14. Mean seasonal cycle, repeated for $2 \mathrm{yr}$ along $95^{\circ} \mathrm{W}$, of (a) three-dimensional temperature balance residual expressed as entrainment velocity $w_{e}$ (in $10^{-3} \mathrm{~cm} \mathrm{~s}^{-1}$ ) and (b) wind stress from QuickSCAT superimposed on TMI SST (repeat of Fig. 11a for reference). Mean entrainment velocity is shown in the right-hand side of (a), superimposed with the mean of upwelling velocity computed from OSCAR currents (black dashed line). Vertical diffusivity $K$ resembles $w_{e}$ very closely in structure, with a scaling of $1 \times 10^{-3}$ $\mathrm{cm} \mathrm{s}^{-1}$ for $w_{e}$ equivalent to $2 \mathrm{~cm}^{2} \mathrm{~s}^{-1}$ for $K$.

relatively steady southeast trade winds and deep mixed layers.

\section{a. Cold tongue region $\left(5^{\circ} \mathrm{N}-5^{\circ} \mathrm{S}\right)$}

The seasonal evolution of entrainment velocity along $95^{\circ} \mathrm{W}$ shows that it is maximum at about $1.2 \times 10^{-3}$ $\mathrm{cm} \mathrm{s}^{-1}$ in late boreal spring (May-June) on the equator (Fig. 14a). This is a time when equatorial SST is decreasing most rapidly as the cold tongue forms, even though surface heat fluxes are heating the ocean at a rate of $O\left(100 \mathrm{~W} \mathrm{~m}^{-2}\right)$ (Fig. 11d). It is also a time when meridional surface divergence in the mixed layer is strongest (Fig. 10). A consistent interpretation of these relationships is that turbulent processes are responsible for mixing cold upwelled water into the surface layer at this time. As the meridional winds intensify in June and July, the region of maximum entrainment and minimum SST both shift upwind and become centered near $2^{\circ} \mathrm{S}$. This upwind shift is consistent with simple dynamical ideas about how Ekman divergence and upwelling respond to meridional wind forcing near the equator (Cromwell 1953; Cane 1979; Philander and Pacanowski 1981; de Szoeke et al. 2007). The annual mean vertical velocity, computed from mean OSCAR currents as $w=$ $h\left[u_{x}+v_{y}\right]$, exhibits the expected hemispheric asymmetry with positive (upwelling) tendencies predominating south of $2^{\circ} \mathrm{N}$ and negative (downwelling) tendencies north of $2^{\circ} \mathrm{N}$ (right-hand side of Fig. 14a). Moreover, in the mean cold tongue region between $0^{\circ}$ and $2^{\circ} \mathrm{S}$, both $w$ (computed from OSCAR) and $w_{e}$ (estimated from the residual of the heat balance) are the same order of magnitude.
It is noteworthy that, although the winds remain steady from the south across the equator during August through November, the entrainment velocity estimated from the residual of the heat balance diminishes at the equator and $2^{\circ} \mathrm{S}$. One would not expect this to happen if the residual were representative primarily of vertical turbulent entrainment and mixing. Moreover, weak negative values of $w_{e}$ are evident on the equator in August to October and north of the equator during May to January when the SST front is strongly developed (Fig. 14b). Negative values of entrainment velocity, which imply detrainment heating, are not physically meaningful given our definition of this process. Similarly, negative values in Fig. 14a, interpreted as diffusivity, indicate physically unrealistic negative values of $K$. These negative values could be the result of analysis error. However, the peculiar spatial and temporal pattern of the negative residuals in Fig. 13b suggests another more physically plausible interpretation, namely, that they represent a missing source of heating due to the poor representation of TIWs in our estimates of advection. An interpretation of the residual only in terms of vertical turbulent processes is thus incomplete.

TIWs are generally most energetic in the latter half of the year with large amplitudes on the equator and in the SST frontal region north of the equator (Hansen and Paul 1984; Halpern et al. 1988; McPhaden 1996; Swenson and Hansen 1999; Chelton et al. 2001; de Szoeke et al. 2007). Moreover, individual TAO time series of $v$ and $T$ from $95^{\circ} \mathrm{W}$ clearly show the signature of 20-30-day period TIWs during 2000-03. There is little evidence, though, of near-equatorial warming as- 
sociated with TIWs in our $v T_{y}$ computation because TIW variance is too small in the OSCAR current analysis. A comparison of $v T_{y}$ computed using monthly $v$ and $T_{y}$ data and monthly-averaged $v T_{y}$ using 5-day $v$ and 5-day $T_{y}$ data shows very little difference near the equator. TAO data have better temporal resolution but are too gappy in space and time to enable meaningful computations of lateral heat fluxes associated with TIWs.

The missing heat source, equivalent to about $0.05^{\circ}-$ $0.1^{\circ} \mathrm{C}$ day $^{-1}$ at $2^{\circ} \mathrm{N}$ during June-August (Fig. $13 \mathrm{c}$ ), is similar in magnitude to the TIW heating rate found along $95^{\circ} \mathrm{W}$ in de Szoeke et al. (2007) and in other model studies summarized therein. Maximum values on the equator are smaller and, at about $0.02^{\circ} \mathrm{C} \mathrm{day}^{-1}$, are only about one-third the estimate derived for TIW heating at $0^{\circ}, 110^{\circ} \mathrm{W}$ in Wang and McPhaden (1999). This zonal contrast suggests that TIW heating is weaker at $95^{\circ} \mathrm{W}$ than at $110^{\circ} \mathrm{W}$, consistent with the de Szoeke et al. (2007) model study and the observed increase in TIW spectral energy levels west of $95^{\circ} \mathrm{W}$ (Halpern et al. 1988).

The maximum inferred TIW heating at $2^{\circ} \mathrm{N}$, integrated over a 25 -m-thick mixed layer is about $120 \mathrm{~W}$ $\mathrm{m}^{-2}$. This value is about twice that found by Swenson and Hansen (1999) for the late boreal summer-to-fall seasonal maximum in the eastern equatorial Pacific based on an analysis of drifter and expendable bathythermograph data. However, they considered the heat balance averaged over a relatively large area $\left(4^{\circ} \mathrm{N}-4^{\circ} \mathrm{S}, 98^{\circ}-130^{\circ} \mathrm{W}\right)$ encompassing regions of both high and low TIW variability.

Invoking a TIW contribution to the temperature balance residual also helps to reconcile the differences in sign between $w$ and $w_{e}$ in the region $0^{\circ}-5^{\circ} \mathrm{N}$ (Fig. 14a). The two in principle are related through the expression $w_{e}=D h / d t+w$. For mean conditions, $w_{e}=w+u h_{x}+$ $v h_{y}$. The mean structure $v h_{y}$, which we expect to be larger than $u h_{x}$ from scaling arguments and which we can estimate directly, is generally much smaller than $w$ along $95^{\circ} \mathrm{W}$. Thus, this expression effectively reduces to $w_{e} \approx w$, an equivalence that approximately holds between $0^{\circ}$ and $5^{\circ} \mathrm{S}$ in the upwelling zone of the southward-displaced cold tongue. We would most likely expect mean detrainment to occur near $4^{\circ}-5^{\circ} \mathrm{N}$ where downwelling from converging meridional currents (Johnson 2001) depresses the mixed layer and thermocline (Fig. 5). The implied detrainment in our mean temperature balance, however, is shifted $2^{\circ}$ equatorward to the SST frontal zone. Thus, the apparent discrepancy between $w$ and $w_{e}$ can be reconciled by interpreting negative $w_{e}$ in Fig. 14a as TIW heating. Similarly, a TIW contribution to the temperature balance residual also helps to explain the apparent de- crease in $w_{e}$ between $0^{\circ}$ and $2^{\circ} \mathrm{S}$ during AugustNovember even though the southerly component of the trades remains strong. Heating from TIWs during this time would counteract cooling from entrainment such that the sum of the two processes would be smaller than the individual magnitudes of either.

\section{b. $\operatorname{ITCZ}\left(8^{\circ}-12^{\circ} \mathrm{N}\right)$}

Variations in the heat balance in the region $8^{\circ}-12^{\circ} \mathrm{N}$ are very different than those on the equator because of the influence of the ITCZ. Here we use $8^{\circ} \mathrm{N}$ to illustrate how this balance evolves seasonally and how the residual cooling relates to dynamic and thermodynamic forcing in this region. Surface heat flux forcing is highest in the early part of the calendar year, causing SST to rise to a boreal spring maximum (Figs. 15a,c). As the region $8^{\circ}-12^{\circ} \mathrm{N}$ warms, the equatorial band cools, and the southerly component of the trades intensifies. Consequently, the ITCZ migrates northward in tandem with the warmest SSTs (e.g., Fig. 11a). As the ITCZ passes over $8^{\circ} \mathrm{N}$ in boreal spring (Fig. 15d), high cloudiness reduces insolation so that temperature in the thin surface mixed layer begins to cool (Figs. 15a-c). At the same time, the Ekman pumping velocity, $w_{\mathrm{Ek}}=-\rho^{-1}$ $\operatorname{curl}(\tau / f)$, where $\tau$ is the vector wind stress and $f$ is the Coriolis parameter, switches from downwelling to upwelling favorable as determined by QuikSCAT wind stresses (Figs. 15d,e). The thermocline is very close to the surface at this location because of doming associated with the eastward flowing NECC (Fig. 5). Thus, the development of positive Ekman pumping velocities in boreal summer facilitates entrainment of cold thermocline water into the thin surface mixed layer (Fig. 15f), which also promotes SST cooling.

A secondary seasonal maximum in surface heat flux subsequently develops in boreal summer (Fig. 15c) because latent heat fluxes are reduced in magnitude as SST cools and because insolation increases as the band of cloudiness in the ITCZ migrates farther north (Fig. 11a). This boreal summer heat flux maximum and related surface mixed layer heating limit the cooling effects of Ekman pumping and entrainment. SSTs thus temporarily plateau before decreasing further. Meanwhile, near-equatorial and southern latitude SSTs begin to warm up in boreal fall, and the ITCZ migrates southward. Zonal advection by the NEC tends to cool SST in boreal winter and spring and to warm in boreal fall, but advection is generally a secondary contributor to the heat balance at these latitudes (Figs. 12c,d). Horizontal heat fluxes associated with eddies generated by gap winds in Central America may also contribute to the seasonal cycle of SST in this region (Wijesekera et al. 2005; Willet et al. 2006). 


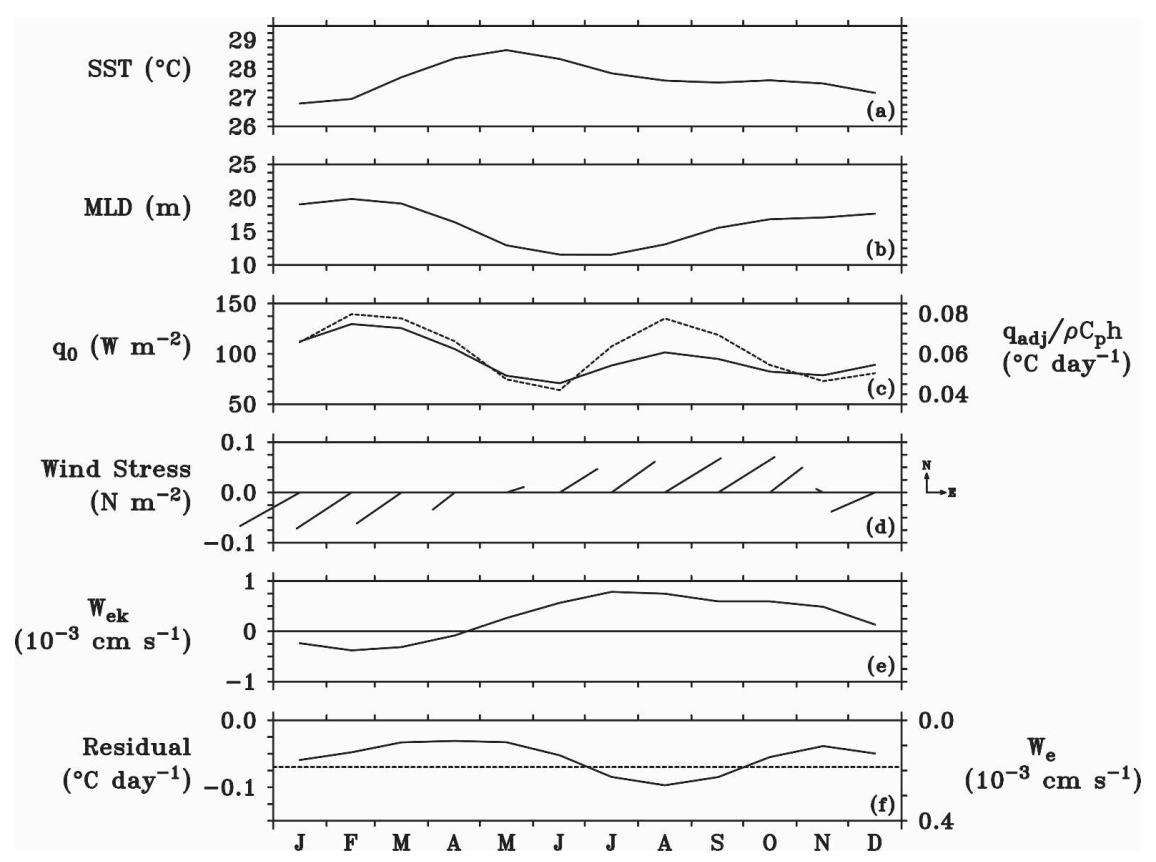

FIG. 15. The mean seasonal cycle at $8^{\circ} \mathrm{N}, 95^{\circ} \mathrm{W}$ of (a) SST, (b) mixed layer depth, (c) net surface heat flux $q_{0}$ (solid line) and the adjusted net surface heat flux $q_{\text {adj }}^{\prime}=q_{\text {adj }} / \rho c_{p} h$ (dashed line), (d) QuikSCAT wind stress, (e) Ekman pumping velocity, and (f) temperature balance residual. Dashed line in (f) shows the $90 \%$ confidence limit of the null hypothesis that the residual is statistically no different from zero. The right axis (with inverted scale) in (f) shows the residual scaled by the annual mean of $-h / \Delta T$, which provides a measure of entrainment velocity. Ekman pumping velocity has been calculated using centered differences on a $\pm 1^{\circ}$ latitude $\times \pm 5^{\circ}$ longitude grid using QuikSCAT wind stress. Time series have been smoothed with a $1-2-1$ monthly filter.

\section{c. Steady southeast trade wind regime $\left(8^{\circ} \mathrm{S}\right)$}

The two largest terms in the mixed layer temperature balance at $8^{\circ} \mathrm{S}, 95^{\circ} \mathrm{W}$ are the temperature tendency and the adjusted net surface heat flux with mean seasonal standard deviations of $0.035^{\circ} \mathrm{C}$ and $0.026^{\circ} \mathrm{C}$ day $^{-1}$, respectively. The advection terms are an order of magnitude smaller (seasonal standard deviations of $0.008^{\circ} \mathrm{C}$ day $^{-1}$ in the zonal direction and $0.002^{\circ} \mathrm{C} \mathrm{day}^{-1}$ in the meridional direction) and not statistically significant. The residual (standard deviation of $0.018^{\circ} \mathrm{C}$ day $^{-1}$ ) is smaller here than at any other latitude and only marginally significant. The largest residuals are in MarchApril at a time of high surface heat flux and relatively weak winds (Fig. 16). It seems unlikely, therefore, that turbulent entrainment is the process responsible for this heat sink since the sources of turbulence generation are not phased properly with the residual. Moreover, the mixed layer is deeper at $8^{\circ} \mathrm{S}$ than at any other location along $95^{\circ} \mathrm{W}$, which would tend to weaken entrainment and its effects on SST. It is more probable that the small residual at this location either is not physically significant or is the result of some other process. One possible mechanism is mesoscale eddy transport of water origi- nating in the coastal upwelling zone to the east, a process that contributes to seasonal cooling in the stratus deck region farther to the south off the coast of Peru and Chile (Colbo and Weller 2007). In any case, the balance at this location is close to one-dimensional most of the time with $T_{t} \approx q_{\text {adj }} / \rho c_{p} h$.

\section{Summary and discussion}

We have used a unique 3-yr dataset collected as part of the EPIC field program to describe seasonal variations in the surface mixed layer temperature balance in the eastern tropical Pacific. Most variability in the region is characterized by a dominant annual cycle despite predominant semiannual forcing in clear-sky radiation. The coupled ocean-atmosphere-land interactions that give rise to the dominant annual periodicity are also responsible for a strong hemispheric asymmetry in mean climatological conditions. Thus, the mean seasonal cycle of SST and the factors that give rise to it have a different character depending on latitude in the eastern tropical Pacific.

Surface heat fluxes are an important component of 


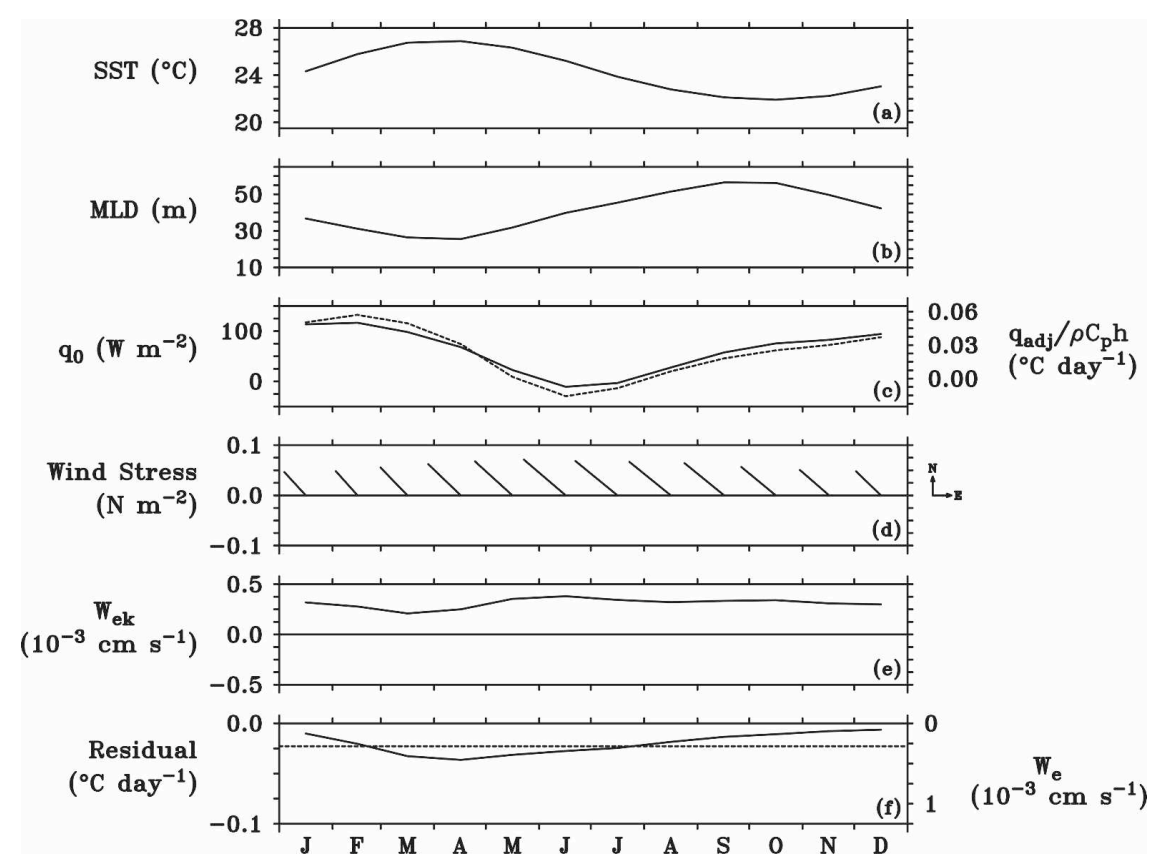

FIG. 16. Same as Fig. 15, but for $8^{\circ} \mathrm{S}, 95^{\circ} \mathrm{W}$.

the mixed layer temperature balance, and on average the ocean gains heat at all latitudes in the region. However, the ocean loses heat from June to November in the SST frontal zone north of the equator, making it a region of minimum annual-mean surface heat flux and maximum seasonal variability of surface heat flux. Conversely, maximum mean heat gain by the ocean occurs just south of the equator $\left(2^{\circ} \mathrm{S}\right)$ in the upwelling region of the equatorial cold tongue.

Large-scale mean zonal trade wind forcing causes the thermocline to tilt down toward the west and to shoal in the east. Mixed layers are therefore relatively thin in the eastern tropical Pacific and have less capacity to store heat than in regions where the thermocline is deeper. Thin mixed layers also enhance the penetrative component of shortwave radiation and are conducive to vertical turbulent exchange with the thermocline. Near the equator, local trade winds cause Ekman divergence and upwelling that facilitate entrainment of cold water into the mixed layer. The southerly component of the trades along $95^{\circ} \mathrm{W}$ moves the center of the upwelling and entrainment upwind into the Southern Hemisphere near $2^{\circ} \mathrm{S}$, while the easterly component of the trades drives a southward Ekman drift in the Southern Hemisphere that spreads the cold upwelled water farther southward. Conversely, the southerly component of the trades produces a strongly convergent flow poleward of $2^{\circ} \mathrm{N}$, restricting the spread of cold upwelled waters into the Northern Hemisphere. Thus, the mean axis of the cold tongue shifts south of the equator, and seasonal variations in the cold tongue SST are more pronounced south of the equator than north along $95^{\circ} \mathrm{W}$.

Surface heat fluxes are largest early in the calendar year between $8^{\circ}$ and $12^{\circ} \mathrm{N}$, when they lead to a boreal spring maximum in SST. Coincident with these maximum springtime temperatures, the equator begins to cool in association with an intensification of the southerly component of the trade winds. The ITCZ shifts northward from its boreal winter location near $4^{\circ} \mathrm{N}$ in concert with these intensified southerly winds and latitudinal SST contrasts, increasing cloudiness and reducing surface heat flux as it passes overhead. Ekman pumping associated with the ITCZ also facilitates the entrainment of cold thermocline water into the mixed layer, particularly in the vicinity of the NECC ridge where the thermocline is very shallow. These processes lower SSTs from their boreal spring maxima between $8^{\circ}$ and $12^{\circ} \mathrm{N}$, favoring a southward shift of the ITCZ later in the year as the equatorial band begins to warm.

Horizontal advection tends to be strongest in the vicinity of the equatorial cold tongue where horizontal SST gradients are large and where the SEC and diverging meridional Ekman flows are pronounced. The advection of heat by seasonally varying currents, however, is generally of secondary importance compared to surface heat fluxes and vertical turbulent processes. At $8^{\circ} \mathrm{S}$, in particular, horizontal advection was insignificant; there the temperature balance involved primarily the storage of surface heat flux in the mixed layer.

A major limitation of our study was the inability to 
accurately estimate the effects of tropical instability waves and other ocean mesoscale eddy processes on the mixed layer temperature balance. TIW fluctuations are evident in individual time series, and our temperature balance analysis suggests their importance, particularly in the SST frontal region north of the equator; however, limited availability of direct velocity measurements and relatively coarse temporal resolution of the OSCAR currents prevented us from quantifying the influence of eddy advection on SST. Moreover, substantial differences between OSCAR and TAO currents imply significant uncertainties in our direct estimates of seasonal advective effects.

Our results support the Mitchell and Wallace (1992) hypothesis about the importance of the increase in the northward surface winds, which they attribute as a response to the onset of the Northern Hemisphere summer monsoon, in reestablishing the Pacific equatorial cold tongue during boreal summer. Our results are also consistent with their assertions about the role of positive feedbacks between the ocean and the atmosphere involving winds, SST, and convective clouds in the ITCZ in regulating climatological conditions in the region. We have, in addition, provided a more detailed oceanographic perspective to their hypothesis by elaborating on the processes that give rise to the mean seasonal cycle of SST. These results may be of value in constraining models of the seasonal cycle in this complicated yet climatically important region of the World Ocean.

Acknowledgments. The authors would like to acknowledge Simon de Szoeke and an anonymous reviewer for very helpful comments on an earlier version of this manuscript. The TAO Project and EPIC field work were supported by NOAA's Climate Program Office and NOAA's Pan American Climate Studies (PACS) program. Production of this manuscript was funded by the Climate Program Office and the Joint Institute for the Study of the Atmosphere and Ocean (JISAO) under NOAA Cooperative Agreement NA17RJ1232, JISAO Publication Number 1409, and PMEL Publication Number 3080. TMI SST data were obtained from ftp://ftp.discover-earth.org/sst/daily/tmi, QuikSCAT wind stress data were obtained from ftp://ftp.ifremer.fr/ifremer/cersat/products/gridded/ mwf-quikscat/, and OSCAR currents were obtained from http://www.oscar.noaa.gov/.

\section{APPENDIX}

\section{Error Estimates for Temperature Balance Analysis}

We estimated uncertainties for various terms in the temperature balance individually and in combination (for the residual) by propagating errors using methods described in Emery and Thompson (1997). We assumed an error of $10 \mathrm{~W} \mathrm{~m}^{-2}$ for the net surface heat flux (based on Cronin et al. 2006b), $10 \mathrm{~cm} \mathrm{~s}^{-1}$ for zonal velocity (based on Fig. 9c), $5 \mathrm{~cm} \mathrm{~s}^{-1}$ for meridional velocity (based on Fig. 10c), a 25\% relative error in mixed layer depth (based on the 5-20 m vertical resolution of temperature sensors), and a $0.1^{\circ} \mathrm{C}$ error in TMI SSTs for horizontal gradient calculations on monthly time scales. To estimate uncertainty in the temperature tendency term, we used the rms difference between $\partial \mathrm{SST} /$ $\partial t$ and the mixed layer tendency $\partial T / \partial t$. As discussed in section $4 \mathrm{a}$, the two should be roughly equivalent under the assumption of a nearly uniform mixed layer temperature. Errors for the primary variables (i.e., velocity, mixed layer depth, etc.) and for individual terms are assumed to be independent and Gaussian distributed.

Time series of individual monthly errors were computed for each term at all latitudes. From these values, the standard error for the monthly mean seasonal cycle was calculated by first computing the rms error for each month across years, then dividing by $\sqrt{ } N$ where $N=1$ to 3 depending on the number of years available (assuming each year is independent). The resultant 12 monthly standard errors for each term of the temperature balance were averaged in time to provide a simple characterization of uncertainties. To estimate standard errors for long-term means, we assumed that the four seasons of the mean seasonal cycle are independent. This assumption leads to an error for long-term means that is half that for the variability. The standard errors we computed by these methods are plotted in Figs. 12 and 13 .

\section{REFERENCES}

Ando, K., and M. J. McPhaden, 1997: Variability of surface layer hydrography in the tropical Pacific Ocean. J. Geophys. Res., 102, $23063-23078$.

Bonjean, F., and G. S. E. Lagerloef, 2002: Diagnostic model and analysis of the surface currents in the tropical Pacific Ocean. J. Phys. Oceanogr., 32, 2938-2954.

Cane, M. A., 1979: The response of an equatorial ocean to simple wind stress patterns: II. Numerical results. J. Mar. Res., 37, 253-299.

Chang, P., 1993: Seasonal cycle of sea surface temperature and mixed layer heat budget in the tropical Pacific Ocean. Geophys. Res. Lett., 20, 2079-2082.

Chelton, D. B., and Coauthors, 2001: Observations of coupling between surface wind stress and sea surface temperature in the eastern tropical Pacific. J. Climate, 14, 1479-1498.

Chen, D., L. W. Rothstein, and A. J. Busalacchi, 1994: A hybrid vertical mixing scheme and its application to tropical ocean models. J. Phys. Oceanogr., 24, 2156-2179.

Colbo, K., and R. A. Weller, 2007: The variability and heat budget 
of the upper ocean under the Chile-Peru stratus. J. Mar. Res., 65, 607-637.

Cromwell, T., 1953: Circulation in a meridional plane in the central equatorial Pacific. J. Mar. Res., 12, 196-213.

Cronin, M. F., and M. J. McPhaden, 1997: The upper ocean heat balance in the western equatorial Pacific warm pool during September-December 1992. J. Geophys. Res., 102, 85338553.

- , and W. S. Kessler, 2002: Seasonal and interannual modulation of mixed layer variability at $0^{\circ}, 110^{\circ} \mathrm{W}$. Deep-Sea Res., 49, 1-7.

- , N. Bond, C. Fairall, J. Hare, M. J. McPhaden, and R. A. Weller, 2002: Enhanced oceanic and atmospheric monitoring underway in the eastern Pacific. Eos, Trans. Amer. Geophys. Union, 83, 205.

$\longrightarrow,-,-$, and R. A. Weller, 2006a: Surface cloud forcing in the east Pacific stratus deck/cold tongue/ITCZ complex. $J$. Climate, 19, 392-409.

— C. Fairall, and M. J. McPhaden, 2006b: An assessment of buoy-derived and numerical weather prediction surface heat fluxes in the tropical Pacific. J. Geophys. Res., 111, C06038, doi:10.1029/2005JC003324.

Davey, M., and Coauthors, 2002: STOIC: A study of coupled model climatology and variability in tropical ocean regions. Climate Dyn., 18, 403-420.

de Szoeke, S. P., C. S. Bretherton, N. A. Bond, M. F. Cronin, and B. M. Morley, 2005: EPIC $95^{\circ} \mathrm{W}$ observations of the eastern Pacific atmospheric boundary layer from the cold tongue to the ITCZ. J. Atmos. Sci., 62, 426-442.

—, S.-P. Xie, T. Miyama, K. J. Richards, and R. J. O. Small, 2007: What maintains the SST front north of the eastern Pacific equatorial cold tongue? J. Climate, 20, 2500-2514.

Emery, W. J., and R. E. Thomson, 1997: Data Analysis Methods in Physical Oceanography. Pergamon Press, 634 pp.

Fairall, C. W., E. F. Bradley, J. S. Godfrey, G. A. Wick, J. B. Edson, and G. S. Young, 1996: Cool-skin and warm-layer effects on sea surface temperature. J. Geophys. Res., 101, 1295-1308.

$\longrightarrow,-$ J. E. Hare, A. A. Grachev, and J. B. Edson, 2003: Bulk parameterization of air-sea fluxes: Updates and verification for the COARE algorithm. J. Climate, 16, 571-591.

Fedorov, A. V., and S. G. H. Philander, 2000: Is El Niño changing? Science, 288, 1997-2002.

Halpern, D., 1987: Observations of annual and El Niño thermal and flow variations at $0^{\circ}, 110^{\circ} \mathrm{W}$ and $0^{\circ}, 95^{\circ} \mathrm{W}$ during 1980 85. J. Geophys. Res., 92, 8197-8212.

_ R. A. Knox, and D. S. Luther, 1988: Observations of 20-day period meridional current oscillations in the upper ocean along the Pacific equator. J. Phys. Oceanogr., 18, 1514-1534.

Hansen, D., and C. Paul, 1984: Genesis and effects of long waves in the equatorial Pacific. J. Geophys. Res., 89, $10431-10440$.

Hayes, S. P., P. Chang, and M. J. McPhaden, 1991: Variability of the sea surface temperature in the eastern equatorial Pacific during 1986-88. J. Geophys. Res., 96, 10 553-10 566.

Johnson, G. C., 2001: The Pacific Ocean subtropical cell surface limb. Geophys. Res. Lett., 28, 1771-1774.

_ B. M. Sloyan, W. S. Kessler, and K. E. McTaggart, 2002: Direct measurements of upper ocean currents and water properties across the tropical Pacific Ocean during the 1990s. Prog. Oceanogr., 52, 31-61.

Kessler, W. S., 2006: The circulation of the eastern tropical Pacific: A review. Prog. Oceanogr., 69, 181-217.

, L. M. Rothstein, and D. Chen, 1998: The annual cycle of
SST in the eastern tropical Pacific, diagnosed in an ocean GCM. J. Climate, 11, 777-799.

Kim, S.-B., I. Fukumori, and T. Lee, 2006: The closure of the ocean mixed layer temperature budget using level-coordinate model fields. J. Atmos. Oceanic Technol., 23, 840-853.

Large, W. G., and G. Danabasoglu, 2006: Attribution and impacts of upper-ocean biases in CCSM3. J. Climate, 19, 2325-2346.

Li, T., and S. G. H. Philander, 1996: On the annual cycle of the eastern equatorial Pacific. J. Climate, 9, 2986-2998.

Lin, J.-L., 2007: The double-ITCZ problem in IPCC AR4 coupled GCMs: Ocean-atmosphere feedback analysis. J. Climate, 20, $4497-4525$.

McPhaden, M. J., 1982: Variability in the central equatorial Indian Ocean. Part II: Oceanic heat and turbulent energy balance. $J$. Mar. Res., 40, 403-419.

_ 1996: Monthly period oscillations in the Pacific North Equatorial Countercurrent. J. Geophys. Res., 101, 6337-6359.

- 2004: Evolution of the 2002-03 El Niño. Bull. Amer. Meteor. Soc., 85, 677-695.

— sphere observing system: A decade of progress. J. Geophys. Res., 103, 14 169-14 240.

Mechoso, C., and Coauthors, 1995: The seasonal cycle over the tropical Pacific in coupled ocean-atmosphere general circulation models. Mon. Wea. Rev., 123, 2825-2838.

Milburn, H. B., P. D. McLain, and C. Meinig, 1996: ATLAS buoy: Reengineered for the next decade. Proc. IEEE/MTS Ocean'96, Fort Lauderdale, FL, IEEE, 698-702.

Mitchell, T. P., and J. M. Wallace, 1992: On the annual cycle in equatorial convection and sea surface temperature. J. Climate, 5, 1140-1156.

Moisan, J. R., and P. P. Niiler, 1998: The seasonal heat budget of the North Pacific: Net heat flux and heat storage rates (195090). J. Phys. Oceanogr., 28, 401-421.

Paulson, C. A., and J. J. Simpson, 1977: Irradiance measurements in the upper ocean. J. Phys. Oceanogr., 7, 952-956.

Philander, S. G. H., and R. C. Pacanowski, 1981: The oceanic response to cross-equatorial winds (with application to coastal upwelling in low latitudes). Tellus, 33, 201-210.

— D. Gu, D. Halpern, G. Lambert, N.-C. Lau, T. Li, and R. C. Pacanowski, 1996: Why the ITCZ is mostly north of the equator. J. Climate, 9, 2958-2972.

Reverdin, G., C. Frankignoul, E. Kestenare, and M. J. McPhaden, 1994: Seasonal variability in the surface currents of the equatorial Pacific. J. Geophys. Res., 99, 20 323-20 344.

Reynolds, R. W., N. A. Rayner, T. M. Smith, D. C. Stokes, and W. Wang, 2002: An improved in situ and satellite SST analysis for climate. J. Climate, 15, 1609-1625.

Swenson, M. S., and D. V. Hansen, 1999: Tropical Pacific Ocean mixed layer heat budget: The Pacific cold tongue. J. Phys. Oceanogr., 29, 69-81.

Taft, B. A., and W. S. Kessler, 1991: Variations of zonal currents in the central tropical Pacific during 1970 to 1987: Sea level and dynamic height measurements. J. Geophys. Res., 96, 12 599-12 618.

Wallace, J. M., T. P. Mitchell, and C. Deser, 1989: The influence of sea surface temperature on surface wind in the eastern equatorial Pacific: Seasonal and interannual variability. $J$. Climate, 2, 1492-1499.

Wang, W., and M. J. McPhaden, 1999: The surface layer heat balance in the equatorial Pacific Ocean. Part I: Mean seasonal cycle. J. Phys. Oceanogr., 29, 1812-1831.

, and - 2001: What is the mean seasonal cycle of surface 
heat flux in the equatorial Pacific? J. Geophys. Res., 106, 837-857.

Wijesekera, H. W., D. L. Rudnick, C. A. Paulson, S. D. Pierce, W. S. Pegau, J. Mickett, and M. C. Gregg, 2005: Upper ocean heat and freshwater budgets in the eastern Pacific warm pool. J. Geophys. Res., 110, C08004, doi:10.1029/2004JC002511.

Willet, C. S., R. R. Leben, and M. F. Lavin, 2006: Eddies and tropical instability waves in the eastern tropical Pacific: A review. Prog. Oceanogr., 69, 218-238.

Xie, S.-P., 1994: On the genesis of the equatorial annual cycle. $J$. Climate, 7, 2008-2013.
— 1996: Westward propagation of latitudinal asymmetry in a coupled ocean-atmosphere model. J. Atmos. Sci., 53, 32363250 .

__ and Coauthors, 2007: A regional ocean-atmosphere model for eastern Pacific climate: Toward reducing tropical biases. J. Climate, 20, 1504-1522.

Yu, X., and M. J. McPhaden, 1999: Seasonal variability in the equatorial Pacific. J. Phys. Oceanogr., 29, 925-947.

Zhang, X., and M. J. McPhaden, 2006: Wind stress variations and interannual sea surface temperature anomalies in the eastern equatorial Pacific. J. Climate, 19, 226-241. 